\title{
In silico investigation of the short QT syndrome, using human ventricle models incorporating electromechanical coupling
}

\author{
Ismail Adeniran ${ }^{1}$, Jules C. Hancox ${ }^{2}$ and Henggui Zhang ${ }^{1,3 *}$ \\ ${ }^{1}$ Computational Biology, Biological Physics Group, School of Physics and Astronomy, The University of Manchester, Manchester, UK \\ 2 School of Physiology and Pharmacology, and Cardiovascular Research Laboratories, School of Medical Sciences, University of Bristol, Bristol, UK \\ ${ }^{3}$ School of Computer Science and Technology, Harbin Institute of Technology, Harbin, China
}

\section{Edited by: \\ Christopher Huang, University of \\ Cambridge, UK}

Reviewed by:

Christopher Huang, University of Cambridge, UK

James A. Fraser, University of

Cambridge, UK

*Correspondence:

Henggui Zhang, Biological Physics Group, School of Physics and Astronomy, The University of Manchester, Room 3.07, Schuster Building, Brunswick Street, Oxford Road, Manchester, M13 9PL, UK e-mail:henggui.zhang@

manchester.ac.uk
Introduction: Genetic forms of the Short OT Syndrome (SOTS) arise due to cardiac ion channel mutations leading to accelerated ventricular repolarization, arrhythmias and sudden cardiac death. Results from experimental and simulation studies suggest that changes to refractoriness and tissue vulnerability produce a substrate favorable to re-entry. Potential electromechanical consequences of the SOTS are less well-understood. The aim of this study was to utilize electromechanically coupled human ventricle models to explore electromechanical consequences of the SOTS.

Methods and Results: The Rice et al. mechanical model was coupled to the ten Tusscher et al. ventricular cell model. Previously validated $\mathrm{K}^{+}$channel formulations for SQT variants 1 and 3 were incorporated. Functional effects of the SQTS mutations on $\left[\mathrm{Ca}^{2+}\right]$ transients, sarcomere length shortening and contractile force at the single cell level were evaluated with and without the consideration of stretch-activated channel current $\left(I_{\text {sac }}\right)$. Without $I_{\text {sac }}$, at a stimulation frequency of $1 \mathrm{~Hz}$, the SOTS mutations produced dramatic reductions in the amplitude of $\left[\mathrm{Ca}^{2+}\right]_{i}$ transients, sarcomere length shortening and contractile force. When $I_{\text {sac }}$ was incorporated, there was a considerable attenuation of the effects of SQTS-associated action potential shortening on $\mathrm{Ca}^{2+}$ transients, sarcomere shortening and contractile force. Single cell models were then incorporated into 3D human ventricular tissue models. The timing of maximum deformation was delayed in the SOTS setting compared to control.

Conclusion: The incorporation of $I_{\mathrm{sac}}$ appears to be an important consideration in modeling functional effects of SQT 1 and 3 mutations on cardiac electro-mechanical coupling. Whilst there is little evidence of profoundly impaired cardiac contractile function in SOTS patients, our 3D simulations correlate qualitatively with reported evidence for dissociation between ventricular repolarization and the end of mechanical systole.

Keywords: short QT syndrome, stretch-activated channel, mechanical contraction, 3D model, human ventricles

\section{INTRODUCTION}

The short QT syndrome (SQTS) was first recognized as a distinct clinical entity in 2000 (Gussak et al., 2000). It is characterized by an abnormally short QT interval on the ECG with a QT interval of $\sim 320 \mathrm{~ms}$ or less, tall and peaked T-waves, and increased $T_{\text {peak }}-T_{\text {end }}$ width (Anttonen et al., 2009; Patel and Pavri, 2009; Couderc and Lopes, 2010; Cross et al., 2011; Gollob et al., 2011). Patients usually have structurally normal hearts and affected families tend to exhibit histories of syncope, abbreviated atrial and ventricular refractory periods, as well as increased susceptibility to atrial and ventricular arrhythmias and sudden death (Gaita et al., 2003; Schimpf et al., 2005; Giustetto et al., 2006; Hancox et al., 2011).

There are currently six identified forms of the genetic SQTS (SQT1-SQT6). SQT1-3 result from gain-of-function mutations to $\mathrm{K}^{+}$channel subunits. For SQT1, these mutations are to the
KCNH2 ( $h E R G$ ) gene encoding the $\alpha$-subunit of the rapidlyactivating delayed rectifier $\mathrm{K}^{+}$channel $I_{\mathrm{Kr}}$ (Brugada et al., 2004; Hong et al., 2005a; Sun et al., 2011). The SQT2 variant arises from mutations to the KCNQ1 gene encoding the $\alpha$-subunit of the slowly-activating delayed rectifier $\mathrm{K}^{+}$channel $I_{\mathrm{Ks}}$ (Bellocq et al., 2004; Hong et al., 2005b), whilst SQT3 involves mutations to the KCNJ2 gene encoding the Kir 2.1 protein, which underlie the inwardly-rectifying $\mathrm{K}^{+}$current $I_{\mathrm{K} 1}$ (Priori et al., 2005; Hattori et al., 2011; Deo et al., 2013). SQT4-SQT6 are due, respectively, to loss-of-function mutations to the CACNA1C, CACNB2b (Antzelevitch et al., 2007) and CACNA2D1 (Templin et al., 2011) genes encoding the $\alpha 1 \mathrm{C}, \beta 2 \mathrm{~b}$, and $\alpha 2 \delta$-1- subunits of the L-type $\mathrm{Ca}^{2+}$ channel.

Pro-arrhythmic mechanisms in the SQTS have been investigated through the application of $\mathrm{K}^{+}$channel openers to left ventricular wedge preparations (e.g., Extramiana and Antzelevitch, 
2004; Patel and Antzelevitch, 2008). Data from these experiments have been suggestive of a role for amplified transmural dispersion of repolarization and abbreviation of effective refractory period in the arrhythmogenic substrate in the SQTS (e.g., Extramiana and Antzelevitch, 2004; Patel and Antzelevitch, 2008). However, at present there are no phenotypically accurate animal models of the SQTS, making in silico approaches attractive for exploring the consequences of identified SQTS mutations. Computer models have reproduced QT interval shortening produced by $\mathrm{K}^{+}$ channel mutations in the syndrome (Zhang and Hancox, 2004; Priori et al., 2005; Weiss et al., 2005; Zhang et al., 2008; Adeniran et al., 2011, 2012; Deo et al., 2013). Using a Markov-model of the N588K-hERG SQT1 mutation based on experimental data from recombinant wild-type and N588K-hERG channels, we have recently shown that this SQT1 mutation reduces substrate size and increases tissue vulnerability to premature stimuli in order to facilitate and maintain re-entrant excitation waves in $2 \mathrm{D}$ and $3 \mathrm{D}$ tissue. We have also shown that the SQT3 D172N Kir2.1 mutation increases tissue vulnerability, alters excitability, stabilizes and accelerates re-entry (Adeniran et al., 2012).

Although the SQTS is an electrical disorder, the heart is both an electrical and mechanical organ and it is feasible, at least in principle, that abbreviated repolarization in the syndrome might influence the mechanical function of the heart. In SQTS patients, there is some evidence of significant dissociation between ventricular repolarization and the end of mechanical systole (Schimpf et al., 2008). All modeling studies to-date that have investigated arrhythmogenesis in the SQTS have utilized ventricular cell and tissue electrical models that do not consider mechanical properties (Zhang and Hancox, 2004; Priori et al., 2005; Weiss et al., 2005; Zhang et al., 2008; Adeniran et al., 2011, 2012; Deo et al., 2013). Through mechano-electric feedback, the heart is able to regulate its electrical activity in response to changes in contractility or volume load (Lab, 1982, 1996; Franz, 1996). This regulation is believed to occur through the activation of stretchactivated channels (SACs) (Taggart, 1996; Bett and Sachs, 1997; Hu and Sachs, 1997; Youm et al., 2005). As potential electromechanical consequences of the SQTS are incompletely understood, the present study was conducted in order: (1) to investigate the potential functional consequences of the SQTS on ventricular contraction at the single cell, tissue and organ levels in the presence and absence of a stretch-activated current $\left(I_{\mathrm{sac}}\right)$ and (2) to evaluate the relationship between ventricular repolarization and mechanical systole in the setting of the SQTS. In order to address these aims, established models of the SQT1 and SQT3 $\mathrm{K}^{+}$-channel-linked SQTS variants (Adeniran et al., 2011, 2012) were coupled to a validated mechanical model (Rice et al., 2008).

\section{MATERIALS AND METHODS}

\section{SOT1 $\left(I_{\mathrm{Kr}}\right)$ AND SOT3 $\left(I_{\mathrm{K} 1}\right)$ FORMULATIONS}

For SQT1, we used a biophysically-detailed Markov chain model formulation which incorporates the experimentally observed kinetic properties of wild-type (WT) and N588K-mutated hERG $/ I_{\mathrm{Kr}}$ channel current at $37^{\circ} \mathrm{C}$ (Adeniran et al., 2011). For SQT3, we employed a biophysically-detailed HodgkinHuxley model formulation (Adeniran et al., 2012), which also incorporates the experimentally observed kinetic properties of the D172N-mutant Kir 2.1 channel at $37^{\circ} \mathrm{C}$.

\section{ELECTROMECHANICAL MODEL}

For electrophysiology, we utilized the ten Tusscher and Panfilov (TP) human ventricular single cell model (Ten Tusscher and Panfilov, 2006), which recapitulates human ventricular cell electrical and membrane channel properties and the transmural heterogeneity of ventricular action potential (AP) across the ventricular wall (Ten Tusscher et al., 2004; Ten Tusscher and Panfilov, 2006). The TP model was modified and updated in 2006 to incorporate newly available experimental data (Xia et al., 2006); these modifications were also employed in the present study. This approach mirrors that used in our recent studies of electrical consequences of the SQT1 and SQT3 mutations (Adeniran et al., 2011, 2012).

We used the Rice et al. myocyte contraction model (Rice et al., 2008) to describe the mechanics of a cardiac myocyte. This model was chosen as it is based on the cross-bridge cycling model of cardiac muscle contraction and is able to replicate a wide range of experimental data including steady-state force-sarcomere length (F-SL), force-calcium and sarcomere length-calcium relations (Rice et al., 2008).

The intracellular calcium concentration $\left[\mathrm{Ca}^{2+}\right]_{i}$ from the electrophysiology model (EP) was used as the coupling link to the myofilament mechanics model $(\mathrm{MM}) \cdot\left[\mathrm{Ca}^{2+}\right]_{i}$ produced as dynamic output from the EP model during the time course of the AP served as input to the MM model from which the amount bound to troponin is calculated. The formulation of the myoplasmic $\mathrm{Ca}^{2+}$ concentration in the EP model is:

$$
\begin{aligned}
\frac{d C a_{i}}{d t}= & C a_{\mathrm{ibufc}}\left(\frac{V_{\mathrm{sr}}}{V_{c}}\left(I_{\text {leak }}-I_{\mathrm{up}}\right)+I_{\mathrm{xfer}}\right) \\
& -C_{m} \frac{I_{\mathrm{bca}}+I_{\mathrm{pca}}-2 I_{\mathrm{NaCa}}}{2 V_{c} F}
\end{aligned}
$$

where $C a_{\mathrm{ibufc}}$ is the total cytoplasmic buffer concentration, $V_{\text {sr }}$ is the sarcoplasmic reticulum (SR) volume, $V_{c}$ is the cytoplasmic volume, $I_{\text {leak }}$ is the SR Ca ${ }^{2+}$ leak current, $I_{\text {up }}$ is the SR $\mathrm{Ca}^{2+}$ pump current, $I_{\text {xfer }}$ is the diffusive $\mathrm{Ca}^{2+}$ current current between dyadic $\mathrm{Ca}^{2+}$ subspace and bulk cytoplasm, $C_{m}$ is the membrane cell capacitance per unit surface area, $I_{\mathrm{bCa}}$ is the background $\mathrm{Ca}^{2+}$ current, $I_{\mathrm{pCa}}$ is the plateau $\mathrm{Ca}^{2+}$ current, $I_{\mathrm{NaCa}}$ is the $\mathrm{Na}^{+} / \mathrm{Ca}^{2+}$ exchanger and $F$ is the Faraday constant.

The flux of the binding of $\mathrm{Ca}^{2+}$ to troponin was incorporated into Equation 1 as follows:

$$
\begin{aligned}
\frac{d C a_{i}}{d t}= & C a_{\mathrm{ibufc}}\left(\frac{V_{\mathrm{sr}}}{V_{c}}\left(I_{\text {leak }}-I_{\mathrm{up}}\right)+I_{\mathrm{xfer}}\right) \\
& -C_{m} \frac{I_{\mathrm{bCa}}+I_{\mathrm{pCa}}-2 I_{\mathrm{NaCa}}}{2 V_{c} F}-\frac{d \operatorname{TropTot}_{\mathrm{Ca}}}{d t} \times \frac{1}{1000}(2)
\end{aligned}
$$

where $\frac{d \operatorname{TropTot}_{\mathrm{Ca}}}{d t}$ is the rate of $\mathrm{Ca}^{2+}$ binding to troponin. The combination of all state variables from the EP model with the MM model and the substitution of (Equation 2) for (Equation 1) yielded a human ventricular myocyte electromechanical cell model. 


\section{STRETCH-ACTIVATED CURRENT}

In accord with previous studies (Kohl and Sachs, 2001; Panfilov et al., 2005; Youm et al., 2005; Kuijpers, 2008; Lunze et al., 2010), we incorporated a stretch-activated current $\left(I_{\mathrm{sac}}\right)$ into the electromechanics model using the following formulation:

$$
I_{\mathrm{sac}}=G_{\mathrm{sac}} \times P_{m} \times\left(V_{m}-E_{\mathrm{sac}}\right)
$$

where $G_{\mathrm{sac}}$ and $E_{\mathrm{sac}}$ are the maximum channel conductance and reversal potential of the SAC, respectively. In the electromechanics model, $E_{\mathrm{sac}}$ was typically set to $1 \mathrm{mV}$ and describes the experimentally observed depolarizing effect of the channel (Kohl et al., 1999; Trayanova et al., 2004). $V_{m}$ is the membrane potential and $P_{m}$ is the channel's open probability modeled as:

$$
P_{m}=\frac{1.0}{1+e^{-\left(\frac{\varepsilon-\varepsilon_{1 / 2}}{k_{\mathrm{e}}}\right)}}
$$

where $\varepsilon$ and $\varepsilon_{1 / 2}$ are the strain (with an explicit dependence on the sarcomere length) and half-activation strain, respectively, $K_{e}=0.02$ (Zabel et al., 1996; Youm et al., 2005; Lunze et al., 2010) is the activation slope.

The SAC is assumed to be permeable to $\mathrm{Na}^{+}, \mathrm{K}^{+}$and $\mathrm{Ca}^{2+}$ (Kamkin et al., 2000; Youm et al., 2005; Kuijpers, 2008) with $I_{\text {sac }}$ therefore defined as:

$$
I_{\mathrm{sac}}=I_{\mathrm{sac}, \mathrm{Na}}+I_{\mathrm{sac}, \mathrm{K}}+I_{\mathrm{sac}, \mathrm{Ca}}
$$

where $I_{\mathrm{sac}, \mathrm{Na}}, I_{\mathrm{sac}, \mathrm{K}}$, and $I_{\mathrm{sac}}, \mathrm{Ca}$ are the contributions of $\mathrm{Na}^{+}$, $\mathrm{K}^{+}$and $\mathrm{Ca}^{2+}$ to $I_{\mathrm{sac}}$. To evaluate the effects of the permeability of the SAC to $\mathrm{Na}^{+}, \mathrm{K}^{+}$, and $\mathrm{Ca}^{2+}$, two permeability ratio cases were considered in the single cell simulations: $P_{\mathrm{Na}}: P_{\mathrm{K}}$ : $P_{\mathrm{Ca}}=1: 1: 0$ and $P_{\mathrm{Na}}: P_{\mathrm{K}}: P_{\mathrm{Ca}}=1: 1: 1$ where $P_{\mathrm{Na}}, P_{\mathrm{K}}$, and $P_{\mathrm{Ca}}$ are the relative permeabilities of the channel to $\mathrm{Na}^{+}, \mathrm{K}^{+}$and $\mathrm{Ca}^{2+}$, respectively.

\section{TISSUE MECHANICS MODEL}

We modeled cardiac tissue mechanics within the theoretical framework of non-linear elasticity (Marsden and Hughes, 1994; Holzapfel, 2000) as an inhomogeneous, anisotropic, nearly incompressible non-linear material similar to previous studies (Hunter et al., 1997; Costa et al., 2001; Whiteley et al., 2007; Niederer and Smith, 2008; Pathmanathan and Whiteley, 2009). We used a two-field variational principle with the deformation $u$ and the hydrostatic pressure $p$ as the two fields (Lions and Ciarlet, 1994; Holzapfel, 2000; Bonet and Wood, 2008). $p$ is utilized as the Lagrange multiplier to enforce the near incompressibility constraint. Thus, the total potential energy functional $\Pi$ for the mechanics problem is formulated as:

$$
\Pi(u, p)=\Pi_{\text {int }}(u, p)+\Pi_{\text {ext }}(u)
$$

where $\Pi_{\text {int }}(u, p)$ is the internal potential energy or total strain energy of the body and $\Pi_{\text {ext }}(u)$ is the external potential energy or potential energy of the external loading of the body. With the axes of the geometry aligned to the underlying tissue microstructure (Seemann et al., 2006; Legrice et al., 1997), the second PiolaKirchhoff stress tensor $S$, obtained from the directional derivative of Equation 6 in the direction of an arbitrary virtual displacement and which relates a stress to a strain measure (Holzapfel, 2000; Bonet and Wood, 2008) is defined as:

$$
S=\frac{1}{2}\left(\frac{\partial W}{\partial E_{\mathrm{MN}}}+\frac{\partial W}{\partial E_{\mathrm{NM}}}\right)-p C_{\mathrm{MN}}^{-1}+S_{\text {ActiveTension }}
$$

where $W$ is a strain energy function that defines the constitutive behavior of the material, $E$ is the Green-Lagrange strain tensor that quantifies the length changes in a material fiber and angles between fiber pairs in a deformed solid, $C$ is the RightCauchy green strain tensor, $p$ is a Lagrange multiplier (referred to as the hydrostatic pressure in the literature) used to enforce incompressibility of the cardiac tissue, $S_{\text {ActiveTension }}$ is a stress tensor incorporating active tension from the electromechanics cell model and enables the reproduction of the three physiological movements of the ventricular wall: longitudinal shortening, wall thickening and rotational twisting (MacGowan et al., 1997; Lorenz et al., 2000; Tseng et al., 2000; Bogaert and Rademakers, 2001; Cheng et al., 2008; Coppola and Omens, 2008; Lilli et al., 2013).

For the strain energy function $W$, we used the Guccione constitutive law (Guccione et al., 1991) given by:

$$
W=C_{1} e^{Q}
$$

Where

$$
Q=C_{2} E_{11}^{2}+C_{3}\left(E_{22}^{2}+E_{33}^{2}+2 E_{23}^{2}\right)+2 C_{4}\left(E_{12} E_{21}+E_{13} E_{31}\right)
$$

following previous work (Land et al., 2012), $C_{1}=0.831 \mathrm{kPa}$, $C_{2}=14.31, C_{3}=4.49, C_{4}=10 . E_{\mathrm{ij}}$ are the components of the Green-Lagrange strain tensor.

\section{TISSUE ELECTROPHYSIOLOGY MODEL}

The monodomain representation (Colli Franzone et al., 2005; Potse et al., 2006; Keener and Sneyd, 2008) of cardiac tissue was used for the electrophysiology model with a modification (the incorporation of the Right Cauchy Green deformation tensor $C$ ), which allows the monodomain equation to take into account the effect of the deforming tissue, similar to previous studies (Nash and Panfilov, 2004; Whiteley et al., 2007; Pathmanathan and Whiteley, 2009):

$$
C_{m} \frac{d V}{d t}=-\left(I_{\text {ion }}+I_{\text {stim }}\right)+\nabla \times\left(D C^{-1} \nabla V\right)
$$

where $C_{m}$ is the cell capacitance per unit surface area, $V$ is the membrane potential, $I_{\text {ion }}$ is the sum of all transmembrane ionic currents from the electromechanics single cell model, $I_{\text {stim }}$ is an externally applied stimulus and $D$ is the diffusion tensor. In simulations, intracellular conductivities in the fiber, cross-fiber and sheet directions were set to $3.0,1.0$, and $0.31525 \mathrm{~ms} \mathrm{~mm}^{-1}$, respectively. These gave a conduction velocity of $65 \mathrm{~cm} \mathrm{~s}^{-1}$ in the 
fiber direction along multiple cells, which is close to the value $70 \mathrm{~cm} \mathrm{~s}^{-1}$ observed in the fiber direction in human myocardium (Taggart et al., 2000).

\section{COMPUTATIONAL METHODS Geometry and meshes}

The 3D simulations were carried out on a DT-MRI reconstructed anatomical human ventricle geometry, incorporating anisotropic fiber orientation, from a healthy 34 -year-old male. This had a spatial resolution of $0.2 \mathrm{~mm}$ and approximately 24.2 million nodes in total and was segmented into distinct ENDO (25\%), MCELL (35\%), and EPI (40\%) regions. The chosen cell proportion in each region is similar to those used in other studies (Gima and Rudy, 2002; Zhang et al., 2008; Adeniran et al., 2011, 2012). The conditional activation sites were determined empirically across the ventricle wall and were validated by reproducing the activation sequence and QRS complex in the measured 64-channel ECG (Keller et al., 2009) of that person.

\section{Solving the electromechanics problem}

The electromechanics problem consists of two sub-problems: the electrophysiology problem and the mechanics problem. The electrophysiology problem (Equation 10) was solved with a Strang splitting method (Sundnes et al., 2005) ensuring that the solution is second-order accurate. It was discretized in time using the Crank-Nicholson method (Burnett, 1987), which is also secondorder accurate and discretized in space with Finite Elements (Burnett, 1987; Braess, 2007; Brenner and Scott, 2010; Ern and Guermond, 2010). $I_{\text {ion }}$ in (Equation 10) represents the single cell electromechanics model from which the active tension input to the Tissue mechanics model for contraction is obtained. The system of ordinary differential equations (ODE) composing $I_{\text {ion }}$ was solved with a combination of the Rush-Larsen scheme (Rush and Larsen, 1978) and the CVODE solver (Cohen et al., 1996; Hindmarsh et al., 2005).

The mechanics problem (Equation 6) was also solved using the Finite element Method using the automated scientific computing library, FEniCS (Logg et al., 2012). The resulting non-linear system of equations was solved iteratively using the Newton method to determine the equilibrium configuration of the system. The value of the Right Cauchy Green Tensor $C$ was then used to update the diffusion coefficient tensor in Equation 10. Over a typical finite element domain, $P_{2}$ elements (Braess, 2007; Brenner and Scott, 2010; Ern and Guermond, 2010) were used to discretize the displacement variable $u$, while the pressure variable $p$ was discretized with $P_{1}$ elements (Braess, 2007; Brenner and Scott, 2010; Ern and Guermond, 2010). This $P_{2}-P_{1}$ mixed finite element has been proven to ensure stability (Chamberland et al., 2010; Haga et al., 2012; Logg et al., 2012) and an optimal convergence rate (Hughes, 2000; Chamberland et al., 2010; Ern and Guermond, 2010).

The algorithm for solving the full electromechanics problem is as follows:

1. Determine the initial deformation and obtain the value of the Right Cauchy Green Tensor $C$.

2. While time $<t_{\text {end }}$ : a. Solve the electrophysiology problem for $\Delta t_{\text {mechanics }}=$ $1 \mathrm{~ms}$ with $C$ as input and active tension $T_{\mathrm{a}}$ as output $\left(\Delta t_{\text {electrophysiology }}=0.01 \mathrm{~ms}\right)$.

b. Project $T_{\mathrm{a}}$ from the electrophysiology mesh onto the mechanics mesh.

c. Solve the mechanics problem with $T_{\mathrm{a}}$ as input and $C$ as output.

\section{RESULTS}

SINGLE CELL ELECTROMECHANICAL SIMULATIONS

\section{Simulations without incorporation of $I_{\text {sac }}$}

Initial simulations, in the absence of $I_{\mathrm{sac}}$, were performed using the coupled electromechanics model for the WT condition for each of ENDO, MCELL, and EPI conditions. Figure 1 shows the electrophysiological consequences of the SQT1 and SQT3 mutations in EPI, MCELL, and ENDO cell types at a stimulation frequency of $1 \mathrm{~Hz}$ (Figures 1Ai-Ci). For the EPI cell, action potential duration at $90 \%$ repolarization $\left(\mathrm{APD}_{90}\right)$ was $317 \mathrm{~ms}$ under WT conditions and was shortened to $212 \mathrm{~ms}$ and $283 \mathrm{~ms}$ respectively under SQT1 and SQT3 conditions. For the MCELL, WT APD 90 was $441 \mathrm{~ms}$, whilst it was 232 and $382 \mathrm{~ms}$ under SQT1 and SQT3 conditions, respectively. For the ENDO cell model, WT $\mathrm{APD}_{90}$ was $317 \mathrm{~ms}$, whilst it was 211 and $284 \mathrm{~ms}$ under SQT1 and SQT3 respectively. The observed APD shortening was more extensive for SQT1 than SQT3 and this is explicable on the basis of the relative timings and roles of $I_{\mathrm{Kr}}$ and $I_{\mathrm{K} 1}$ during ventricular AP repolarization. As shown in Figures 1Aii-Cii, the SQT1 N588K mutation produced a large increase in $I_{\mathrm{Kr}}$ together with a change in the current's profile that resulted in a significant augmentation of $I_{\mathrm{Kr}}$ and shift in timing of maximal current to be earlier during the AP plateau (see also Adeniran et al., 2011). The D172N mutation significantly increased $I_{\mathrm{K} 1}$ magnitude (Figures 1 Aiii-Ciii), but as $I_{\mathrm{K} 1}$ contributes to terminal AP repolarization, the consequence of the mutation for APD shortening was less extensive than that for the SQT1 mutation. The electrophysiological consequences of the SQT1 and SQT3 mutations in these simulations are comparable to those reported previously from non-mechanically coupled ventricular cell models (Adeniran et al., 2011, 2012).

To validate the electromechanics model, we simulated forcefrequency relationship (FFR) by stimulating the single cell at different frequencies for 1000 beats until steady state, recorded the maximum force developed and plotted it against frequency and compared it to experimental data (Mulieri et al., 1992). The results are shown in Figure 2. In the frequency range, $1-2 \mathrm{~Hz}$, the electromechanics model produced an FFR which is qualitatively comparable to experimental data (vertical dashed lines) (Mulieri et al., 1992) and showed the Bowditch staircase or Treppe effect (Woodworth, 1902; Mulieri et al., 1992; Lakatta, 2004). All subsequent simulations in this study were carried out at $1 \mathrm{~Hz}$. We then proceeded to characterize the calcium and contractile properties of the electromechanically coupled WT cell models. Figure 3 shows the action potential (AP), $\left[\mathrm{Ca}^{2+}\right]_{i}$ transient, sarcomere length shortening (SLs): EPI (Figures 3Ai-Aiv), MCELL (Figures 3Bi-Biv), and ENDO (Figures 3Ci-Civ). The larger $\left[\mathrm{Ca}^{2+}\right]_{i}$ transient (and hence contraction) of the MCELL compared to EPI and ENDO cells is consistent with experimental data (McIntosh et al., 2000). 

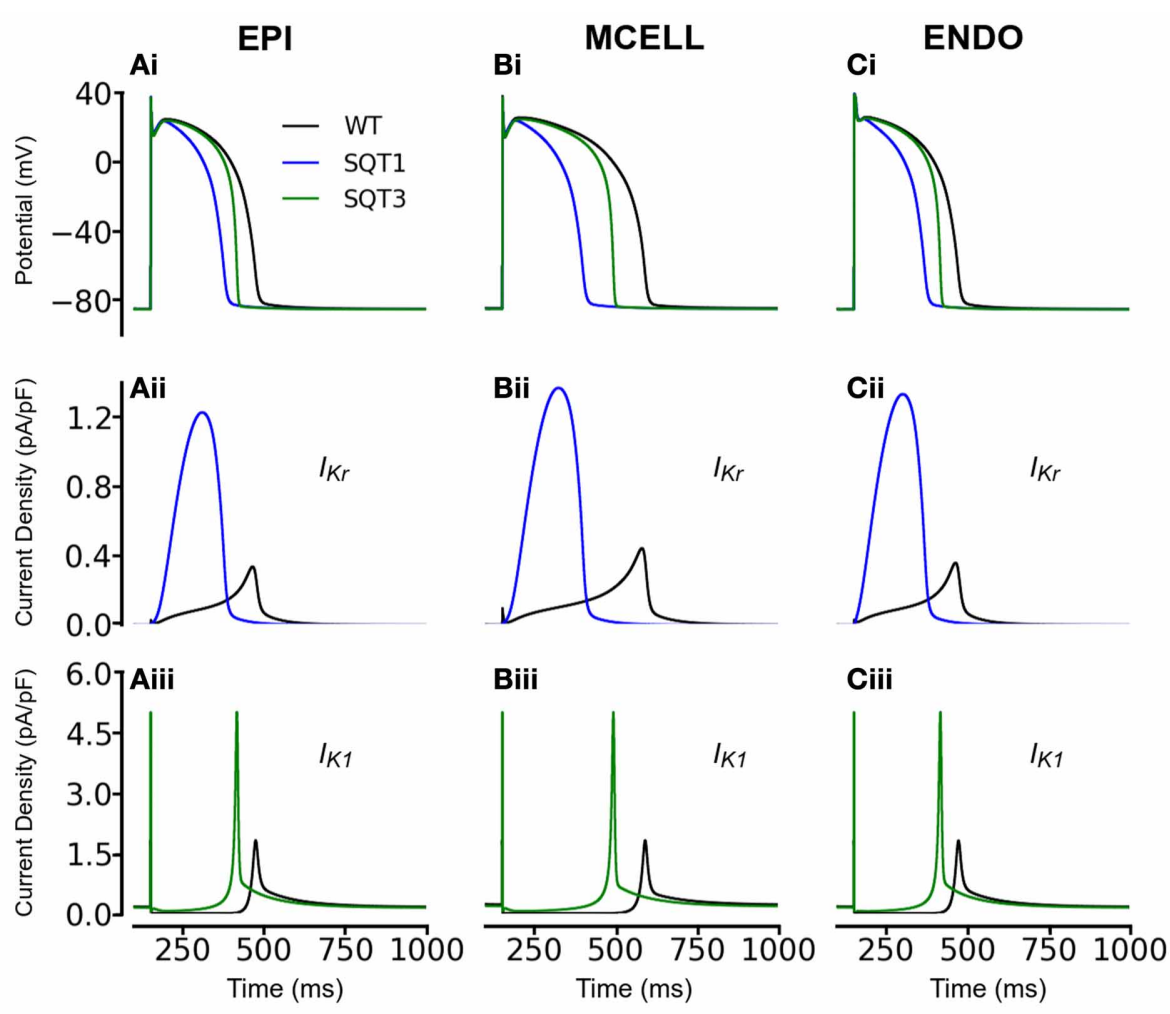

FIGURE 1 | Simulation of ventricular action potentials and the time course of $I_{\mathbf{K r}}$ and $I_{\mathbf{K} 1}$. (Ai-Ci) Steady state (at a stimulation frequency of $1 \mathrm{~Hz}$ ) action potentials for EPI (Ai), MCELL (Bi), and ENDO (Ci) cells under wild-type (WT; black), SQT1 (blue) and SOT3 (green) conditions. (Aii-Cii)
Corresponding $/ \mathrm{K}_{r}$ current profiles for EPI (Aii), MCELL (Bii), and ENDO (Cii) cells under the WT (black) and SQT1 (blue) conditions. (Aiii-Ciii) Corresponding $/ k_{1}$ current profiles for EPI (Aiii), MCELL (Biii), and ENDO (Ciii) cells under the WT (black) and SOT1 (blue) conditions.

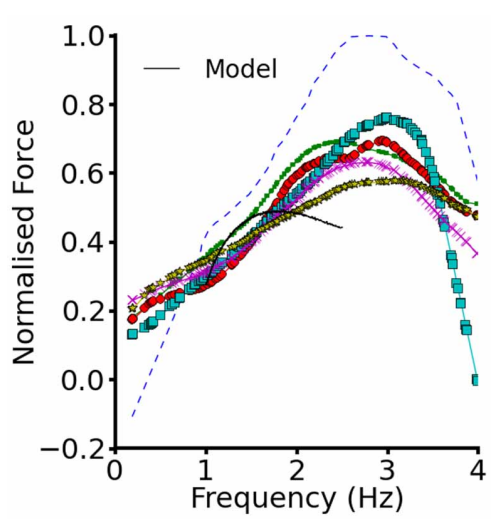

FIGURE 2 | Force-frequency relationship. Plot of steady state normalized active force vs. heart rate using the EPI cell model. Black continuous line represents the WT electromechanics model while symbols represent experimental data from non-failing control preprarations of human myocardium. Experimental data from Mulieri et al. (1992).

Figure 3 also shows the effects of incorporating the SQT1 and SQT3 mutations on the AP, $\left[\mathrm{Ca}^{2+}\right]_{i}$ transient, SL shortening and active force in the coupled electromechanics single cell models. Both mutations shortened the AP (Figures $\mathbf{3 A i}-\mathbf{C i}$ ), reduced the amplitude of $\left[\mathrm{Ca}^{2+}\right]_{i}$ (Figures 3Aii-Cii) and SL shortening (Figures 3Aiii-Ciii) in each of the EPI, MCELL, and ENDO cell models. These effects led to the attenuation of contractility (percentage of WT) in all the cell types (Figures 3Aiv-Civ) (SQT1 EPI 30\%; SQT3 EPI 76\%; SQT1 MCELL 44\%; SQT3 MCELL 83\%; SQT1 ENDO 41\%; SQT3 ENDO 78\%). As identified in Figure 1, the effects for the SQT3 mutation were not as pronounced as the SQT1 mutation because of the relative timing of $I_{\mathrm{Kr}}$ and $I_{\mathrm{K} 1}$ during the AP, with the SQT3 mutation influencing only terminal repolarization and consequently giving rise to longer APDs across the ventricular wall.

The observed reduction in the active force under the mutation conditions in Figure 3 was profound, particularly in the case of SQT1. In order to elucidate the mechanism causing such a decrease in contractile force, we performed a simulated "AP clamp" experiment on the WT electromechanics model (Figure 4), using two different AP profiles-one AP of a normal duration and the other AP with an abbreviated duration. In this experiment, WT $I_{\mathrm{Kr}}$ and $I_{\mathrm{K} 1}$ formulations were used, therefore any observed alterations to $\left[\mathrm{Ca}^{2+}\right]_{i}$ and contractile force would relate to APD per se. Figure 4 A shows the two AP clamp commands used. Figure 4B shows the AP-evoked $I_{\mathrm{CaL}}$ whilst Figures $4 \mathrm{C}-\mathrm{E}$ respectively show $\left[\mathrm{Ca}^{2+}\right]_{i}$, active force, and the difference in steady state level of free calcium concentration in the sarcoplasmic reticulum (CaSR). The results of these simulations 

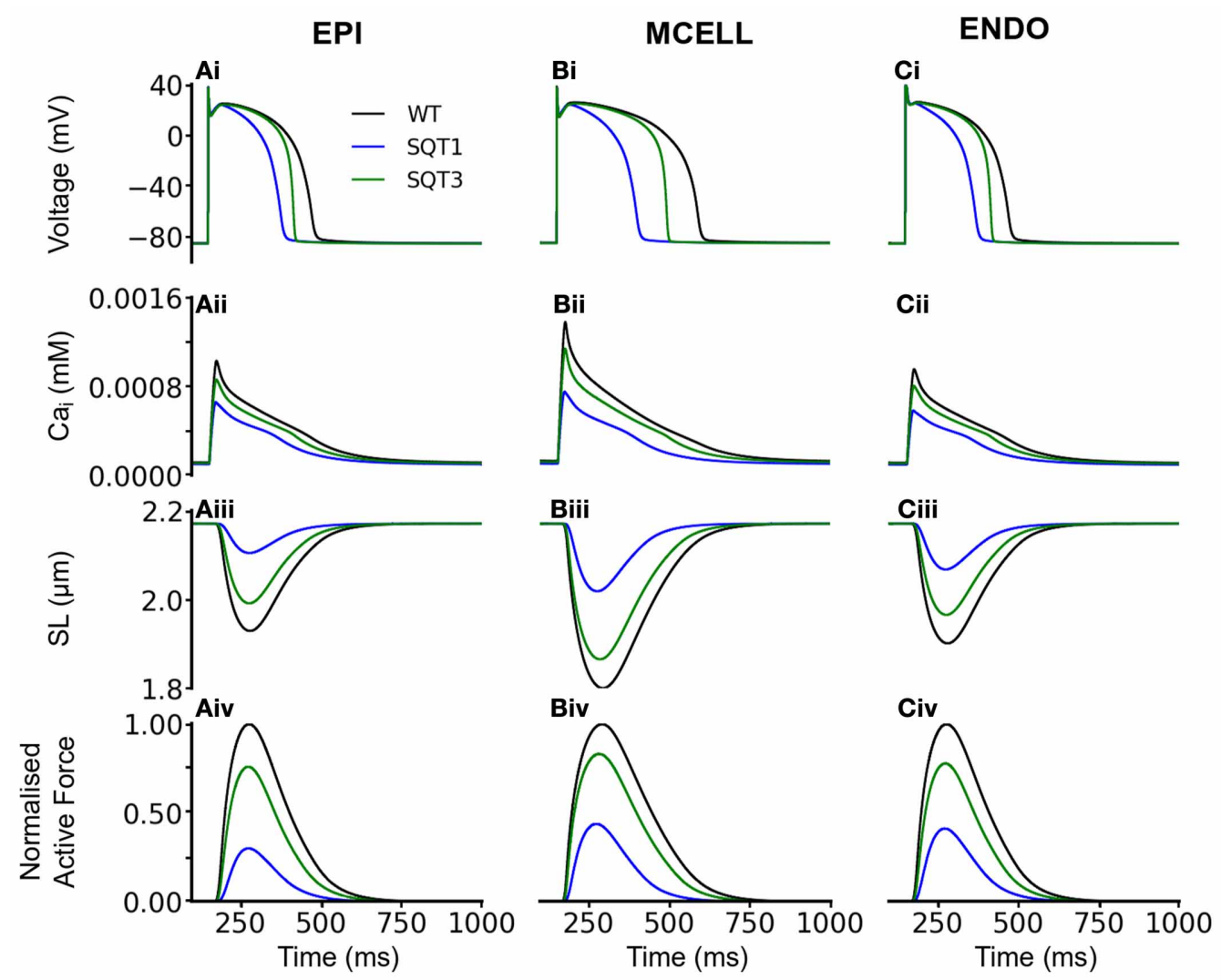

FIGURE 3 | Single cell effects of the SOT1 and SOT3 mutations (without $I_{\text {sac }}$ ). (Ai-Ci) WT (black), SQT1 (blue) and SQT3 (green) action potentials in the EPI (Ai), MCELL (Bi), and ENDO (Ci) cell models. (Aii-Cii) WT (black), SQT1 (blue) and SQT3 (green) intracellular calcium concentration and $\mathrm{Ca}^{2+}$ transients in the EPI (Aii), MCELL (Bii), and ENDO (Cii) cell models.
(Aiii-Ciii) WT (black), SQT1 (blue) and SQT3 (green) sarcomere length (SL) in the EPI (Aiii), MCELL (Biii), and ENDO (Ciii) cell models. (Aiv-Civ) WT (black), SQT1 (blue) and SQT3 (green) active force in the EPI (Aiv), MCELL (Biv), and ENDO (Civ) cell models. Values are normalized to WT maximum active force for each cell type. showed that though the shorter AP did not alter notably the peak amplitude of $I_{\mathrm{CaL}}$, it reduced the amplitude of the $\left[\mathrm{Ca}^{2+}\right]_{i}$ transient, SL shortening and the active force and-notably-SR calcium content (CaSR). These effects are similar to the results shown in Figure 3 for the SQT models. However, in the AP clamp simulation, any observed reduction in amplitude of $\left[\mathrm{Ca}^{2+}\right]_{i}, \mathrm{SL}$ shortening, CaSR and the active force can be attributed solely to consequences of application of the shorter AP waveform. This suggests that the key reason for the reduced active force in the SQTS setting (Figure 3) is the indirect effect of the SQT mutationlinked AP shortening on $\mathrm{Ca}^{2+}$ handling (and on SR content in particular).

To investigate further the functional impact of AP duration on the loading of SR calcium content at the steady state, we applied conditioning trains containing one of two different AP clamp commands (one with a longer and the other with a shorter AP duration) to the WT electromechanics model; the conditioning train was followed by an identical single square voltage command to $+10 \mathrm{mV}$ for $300 \mathrm{~ms}$ (Figure 5A). With the conditioning train of APs comprised of the longer duration AP, it was observed that the $+10 \mathrm{mV}$ square pulse command produced a larger $\left[\mathrm{Ca}^{2+}\right]_{i}$ transient than that when conditioning trains of shorter duration APs were applied. Results are shown in Figure 5C. With the conditioning AP trains of different durations, the square pulse elicited an identical $I_{\mathrm{CaL}}$ (Figure 5B), but a smaller $\left[\mathrm{Ca}^{2+}\right]_{i}$ amplitude (Figure 5C) and active force (Figure 5D) for the shorter duration AP. These simulations also showed that prior to the square pulse command, the SR was filled to a greater level with the longer duration conditioning APs than with those of shorter duration, (as illustrated by the steady state CaSR in Figure 5E). This further validates the notion that the attenuation of $\left[\mathrm{Ca}^{2+}\right]_{i}$ amplitude and contractility with the SQT mutations was consequent upon reduced SR content associated with abbreviation of AP duration.

\section{Incorporation of $I_{\text {sac }}$}

We then performed comparable simulations with the incorporation of $I_{\mathrm{sac}}$. Figures 6, 7 show the results with the SAC assumed to be permeable to $\mathrm{Na}^{+}, \mathrm{K}^{+}$and $\mathrm{Ca}^{2+}$ in the ratio 1:1:0 (Figure 6) and 1:1:1 (Figure 7). The resting potential for EPI, MCELL and ENDO decreased from -86 to $-76 \mathrm{mV}\left(I_{\mathrm{sac}}\right.$ at 1:1:0 permeability ratio) and to $-79 \mathrm{mV}\left(I_{\mathrm{sac}}\right.$ at 1:1:1 permeability ratio) for the WT 


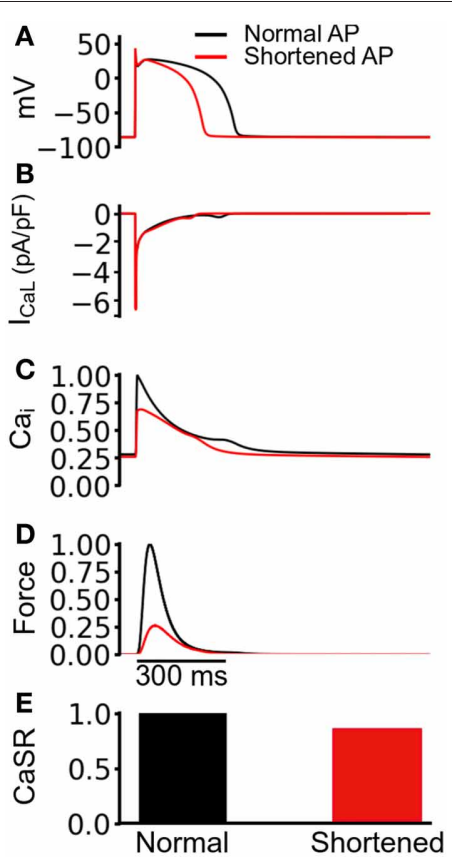

FIGURE 4 | Simulated AP clamp using the WT electromechanics model without $\boldsymbol{I}_{\text {sac }}$. (A) The normal (black) and shortened (red) AP waveforms applied as voltage clamp commands to the WT electromechanics model. (B) $I_{\text {CaL }}$ elicited by the two AP waveforms in (A). (C) Normalized $\left[\mathrm{Ca}^{2+}\right]$ elicited by the two AP waveforms in (A). Values are normalized to maximum $\left[\mathrm{Ca}^{2+}\right]_{i}$ for the "normal" AP waveform. (D) Normalized SL shortening elicited by the two AP waveforms in (A). Values are normalized to maximum SL shortening for the normal AP waveform. (E) Normalized contractile force elicited by the two AP waveforms in (A). Values are normalized to maximum active force for the normal AP waveform.

and SQT1 conditions respectively. Depolarization of the membrane potential is an effect of SACs, which has been observed experimentally (Boland and Troquet, 1980; Franz et al., 1992; Kamkin et al., 2000). The resting membrane potential remained unchanged under the SQT3 condition because the increase in outward $I_{\mathrm{K} 1}$ caused by the mutation counteracted the depolarizing effect of $I_{\mathrm{sac}}$. Similar to the situation without $I_{\mathrm{sac}}$, the incorporation of SQT1 and SQT3 mutations abbreviated the AP in all three cell types (Figures $\mathbf{6 A i}-\mathbf{C i}, \mathbf{7 A i}-\mathbf{C i}$ ). The most significant consequences of inclusion of $I_{\text {sac }}$ were upon $\left[\mathrm{Ca}^{2+}\right]_{i}$ and contractile activity. Thus, the results shown in Figures 6, 7 indicate that incorporation of $I_{\mathrm{sac}}$ attenuated the reduction caused by the SQT1 and SQT3 mutations shown in Figure 3 on $\left[\mathrm{Ca}^{2+}\right]_{i}$ (Figures 6Aii-Cii, 7Aii-Cii), SLs (Figures 6Aiii-Ciii, 7Aiii-Ciii) and active force (Figures 6Aiv-Civ, 7Aiv-Civ). $I_{\mathrm{sac}}$ incorporated at 1:1:1 permeability ratio (i.e., incorporating $\mathrm{Ca}^{2+}$ permeability) produced the greater effect, with contractility across the ventricular wall being approximately $85 \%$ of control under the SQT1 mutation and $92 \%$ of control under the SQT3 mutation. In contrast, with $I_{\text {sac }}$ incorporated at a permeability ratio of 1:1:0, on average across the ventricular wall, the contractile force was $62 \%$ of control under the SQT1 condition and $82 \%$ of control under the SQT3 condition.

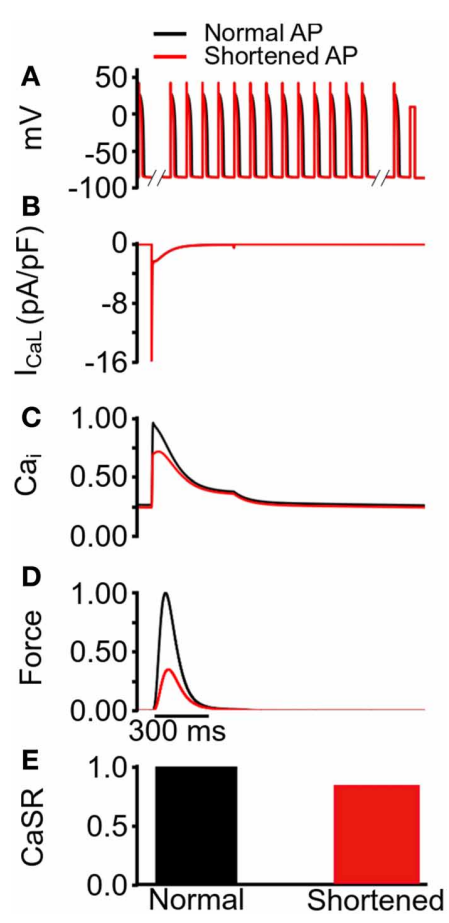

FIGURE 5 | Changes in steady state SR content induced by conditioning trains of action potentials of differing duration. (A) Protocol used to determine steady state SR content, comprised of train of 100 normal (black) and shortened (red) AP clamp commands followed by a $300 \mathrm{~ms}$ square command voltage pulse to $+10 \mathrm{mV}$. (B) / CaL elicited by the $+10 \mathrm{mV}$ voltage command. Peak $I_{\mathrm{CaL}}$ is equal with the two AP waveforms in (A). (C) Normalized $\left[\mathrm{Ca}^{2+}\right]_{i}$ elicited by the by the $+10 \mathrm{mV}$ voltage command. Values are normalized to maximum $\left[\mathrm{Ca}^{2+}\right]_{i}$ for the "normal" AP waveform. (D) Normalized active force elicited by the $+10 \mathrm{mV}$ voltage command. Values are normalized to maximum active force for the normal AP waveform. (E) Normalized maximum SR Ca ${ }^{2+}$ content prior to the application of $+10 \mathrm{mV}$ voltage command in (A). Values are normalized to maximum SR $\mathrm{Ca}^{2+}$ for the normal AP waveform.

In order to investigate how $I_{\mathrm{sac}}$ attenuated the effects of the SQT1 and SQT3 mutations on $\left[\mathrm{Ca}^{2+}\right]_{i}$ and cell contractility, a side-by-side comparison was made between the effects of the SQT1 and SQT3 mutations on AP duration, $\left[\mathrm{Ca}^{2+}\right]_{i}$ and force production, in the absence of $I_{\mathrm{sac}}$ and with $I_{\mathrm{sac}}$ incorporated at the two permeability ratios (Figure 8). Figures 8Ai-Ci shows that the incorporation of $I_{\mathrm{sac}}$ at both permeability ratios reduced the APDs under the WT, SQT1 or SQT3 conditions, with a greater APD reduction in the case of permeability ratio of $1: 1: 1$ than that of 1:1:0 as shown in Table 1 . There was a greater $\left[\mathrm{Ca}^{2+}\right]_{i}$ transient amplitude under both SQTS mutation conditions with the incorporation of $I_{\text {sac }}$; the greatest amplitude being at the 1:1:1 permeability ratio (Figures 8Aii-Cii). From Figures 8Aiii-Ciii, it is clear to see the increase in the $\left[\mathrm{Ca}^{2+}\right]_{i}$ produced a greater SL shortening (relative to WT) on incorporation of $I_{\mathrm{sac}}$, which consequently led to greater cell contractility in the SQT1 and SQT3 mutations particularly with a permeability ratio of $1: 1: 1$ (Figures 8Aiv-Civ).

We then investigated how the incorporation of $I_{\text {sac }}$ led to better maintenance of the $\left[\mathrm{Ca}^{2+}\right]_{i}$ transient magnitude. Figure 9 shows 

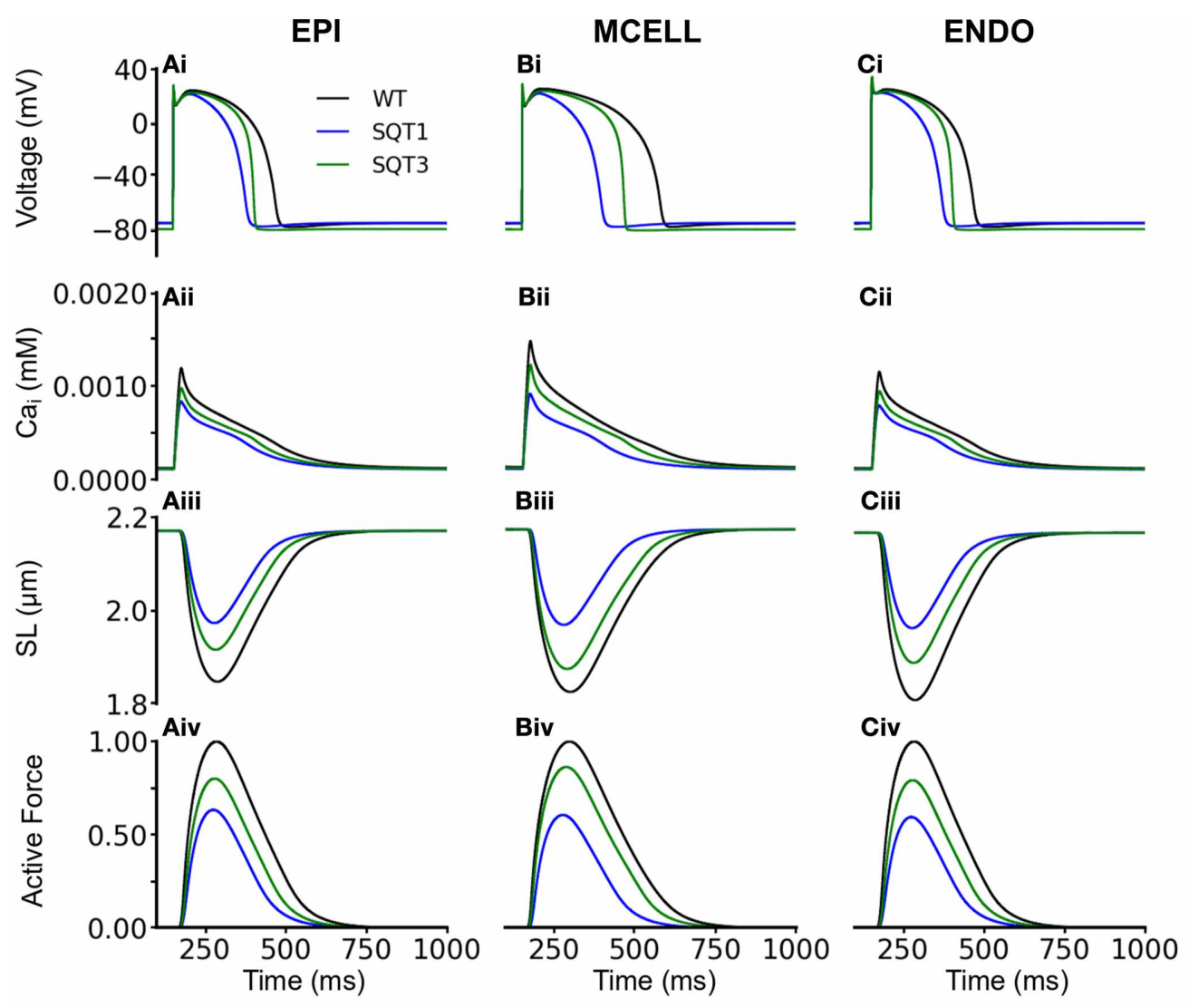

FIGURE 6 | Effects of $I_{\text {sac }}$ on the WT, SOT1, and SOT3 electromechanics model. (Ai-Ci) WT (black), SQT1 (blue) and SQT3 (green) action potentials in the EPI (Ai), MCELL (Bi), and ENDO (Ci) cell models. (Aii-Cii) WT (black), SOT1 (blue) and SOT3 (green) intracellular calcium concentration and $\mathrm{Ca}^{2+}$ transients in the EPI (Aii),
MCELL (Bii), and ENDO (Cii) cell models. (Aiii-Ciii) WT (black), SQT1 (blue) and SQT3 (green) sarcomere length (SL) in the EPI (Aiii), MCELL (Biii), and ENDO (Ciii) cell models. (Aiv-Civ) WT (black), SQT1 (blue) and SOT3 (green). SAC in these simulations were permeable to $\mathrm{Na}^{+}$, $\mathrm{K}^{+}$, and $\mathrm{Ca}^{2+}$ in the ratio $1: 1: 0$. the computed APs (Figures 9Ai-Ci), $I_{\mathrm{CaL}}$ (Figures 9Aii-Cii), $\left[\mathrm{Na}^{+}\right]_{i}$ (Figures 9Aiii-Ciii), $\left[\mathrm{Ca}^{2+}\right]_{i}$ (Figures 9Aiv-Civ), CaSR (Figures 9 Av-Cv) and $I_{\mathrm{NaCa}}$ (Figures 9 Avi-Cvi) with and without $I_{\text {sac }}$ (permeability ratio 1:1:1) in the WT, SQT1 and SQT2 conditions. Under the WT, SQT1 and SQT3 conditions, it was shown that incorporation of $I_{\mathrm{sac}}$ did not produce a noticeable change in the amplitude of $I_{\mathrm{CaL}}$, but elevated $\left[\mathrm{Na}^{+}\right]_{i},\left[\mathrm{Ca}^{2+}\right]_{i}$, and CaSR. These changes in the intracellular $\mathrm{Na}^{+}$and $\mathrm{Ca}^{2+}$ concentrations were associated with an altered $I_{\mathrm{NaCa}}$ as shown in Figures 9Avi-Cvi. In the case when $I_{\mathrm{sac}}$ was absent, during the initial depolarization phase of the AP, $I_{\mathrm{NaCa}}$ operated briefly in its reverse-mode that brought $\mathrm{Ca}^{2+}$ into the cytoplasmic space, producing an outward $I_{\mathrm{NaCa}}$. During the plateau and early repolarization phases, $I_{\mathrm{NaCa}}$ remained almost zero for a period before switching to a forward mode to extrude $\mathrm{Ca}^{2+}$ out of cell cytoplasmic space, producing an inward $I_{\mathrm{NaCa}}$ current in the late repolarization phase. However, in the case with $I_{\mathrm{sac}}$, the activation of $I_{\text {sac }}$ brought more $\mathrm{Na}^{+}$into the cell cytoplasmic space (as it is permeable to $\mathrm{Na}^{+}$) producing an elevated level of $\left[\mathrm{Na}^{+}\right]_{i}$ (Figures 9Aiii-Ciii) as compared to the case when $I_{\mathrm{sac}}$ was absent. Consequently, $I_{\mathrm{NaCa}}$ operated longer in a reverse-mode during the AP phase before it reverted to a normal mode in late repolarization phase. This led to a greater $I_{\mathrm{NaCa}}$ amplitude in both the reverse and forward modes (Figures 9 Avi-Cvi). A greater $I_{\mathrm{NaCa}}$ in the reverse-mode brought more $\mathrm{Ca}^{2+}$ into the cell cytoplasmic space, resulting in a higher systolic level of $\left[\mathrm{Ca}^{2+}\right]_{i}$ (Figures 9 Aiv-Civ) and a greater level of the CaSR (Figures 9Av-Cv). Though this observation was qualitatively similar for the WT (Figure 9Avi), SQT1 (Figure 9Bvi) and SQT3 conditions (Figure 9Cvi), in quantitative terms the increase in the $\left[\mathrm{Ca}^{2+}\right]_{i}$ was more dramatic in the SQT1 and 3 than WT settings. Thus, incorporation of $I_{\mathrm{sac}}$ into the simulations increased $\left[\mathrm{Ca}^{2+}\right]_{i}$ by $88 \%$ under the WT condition, but by $153 \%$ under the SQT 1 condition and by $94 \%$ under the SQT3 setting. The greater increase of $\left[\mathrm{Ca}^{2+}\right]_{i}$ under the SQT simulation conditions provides an explanation for the maintenance of the $\mathrm{Ca}^{2+}$ transient by $I_{\text {sac }}$. Our simulated elevation of $\left[\mathrm{Na}^{+}\right]_{i}$ by $I_{\mathrm{sac}}$ is consistent with previous experimental studies (Alvarez et al., 1999; Isenberg et al., 2003; Youm et al., 2005) that have shown an increase in cytosolic and total $\left[\mathrm{Na}^{+}\right]_{i}$ by a mechanical stretch in human, mouse and ventricular myocytes, which has been attributed to the reversemode of $I_{\mathrm{NaCa}}$ during the rising phase of APs (Gannier et al., 1996; 


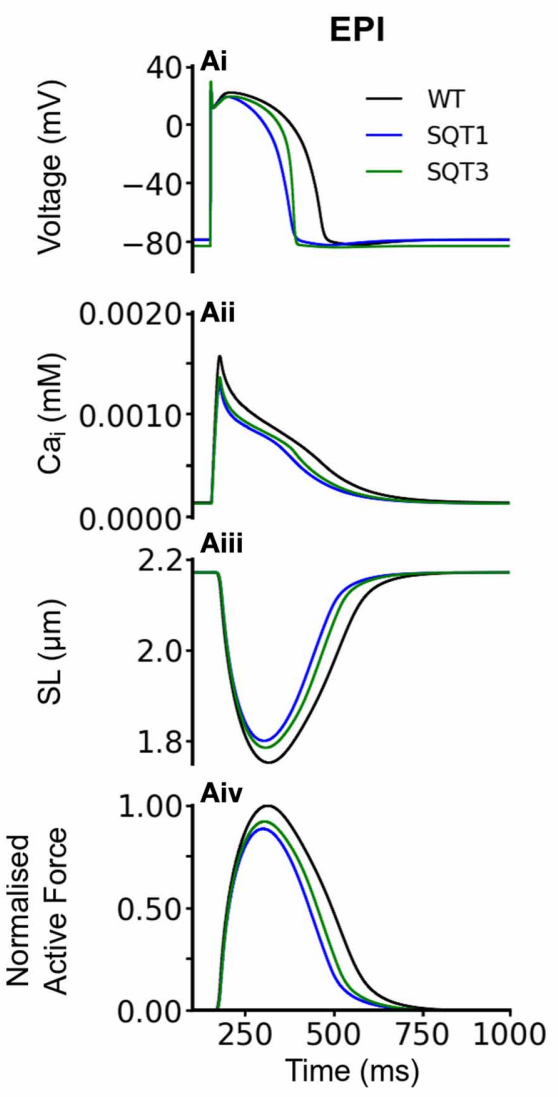

FIGURE 7 | Effects of $I_{\text {sac }}$ on the WT, SOT1, and SOT3

electromechanics model. (Ai-Ci) WT (black), SQT1 (blue) and SQT3 (green) action potentials in the EPI (Ai), MCELL (Bi), and ENDO (Ci) cell models. (Aii-Cii) WT (black), SQT1 (blue) and SQT3 (green) intracellular calcium concentration and $\mathrm{Ca}^{2+}$ transients in the EPI (Aii),
MCELL
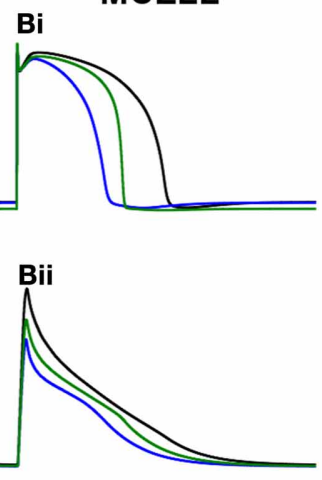

Biii
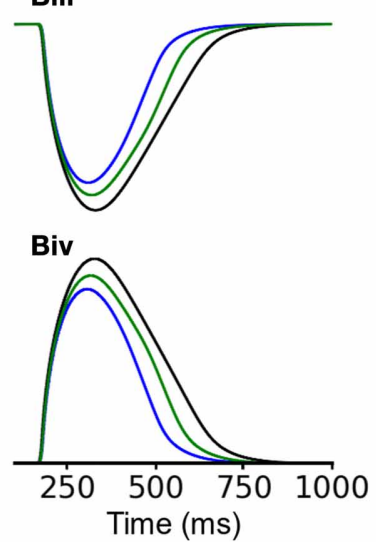

ENDO

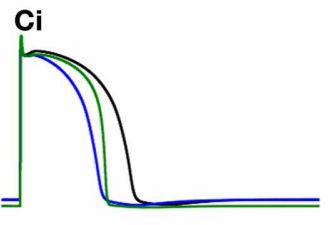

Cii
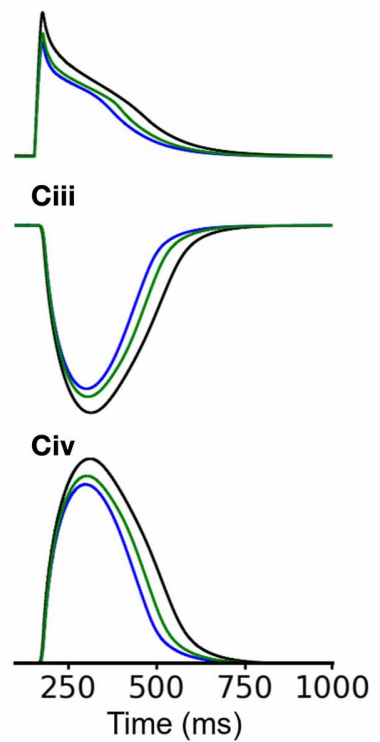

MCELL (Bii), and ENDO (Cii) cell models. (Aiii-Ciii) WT (black), SQT1 (blue) and SQT3 (green) sarcomere length (SL) in the EPI (Aiii), MCELL (Biii), and ENDO (Ciii) cell models. (Aiv-Civ) WT (black), SQT1 (blue) and SQT3 (green). SAC in these simulations were permeable to $\mathrm{Na}^{+}, \mathrm{K}^{+}$, and $\mathrm{Ca}^{2+}$ in the ratio $1: 1: 1$.

Alvarez et al., 1999; Calaghan and White, 1999; Kamkin et al., 2000, 2003; Calaghan et al., 2003; Youm et al., 2005).

\section{D SIMULATIONS}

Results from single cell models cannot be translated automatically to the intact tissue situation due to intercellular electrical coupling and mechanical deformation of tissue. Schimpf et al. (2008) observed a dissociation between ventricular repolarization and the end of mechanical systole in SQT patients. Consequently, to investigate this observation, we implemented a multi-cellular $3 \mathrm{D}$ tissue model of the human ventricles that considered the intercellular electrical coupling and mechanical deformation of tissue. Simulation results using the human ventricle $3 \mathrm{D}$ model are shown in Figure 10. Figure 10A shows the ventricles during diastole before contraction, whilst Figure 10B shows deformation under the WT condition; maximum deformation occurred at $230 \mathrm{~ms}$. Maximum deformation occurred at $200 \mathrm{~ms}$ and $210 \mathrm{~ms}$ under the SQT1 (Figure 10C) and SQT3 (Figure 10D) conditions respectively but in contrast to $\mathrm{WT}$, repolarization had already advanced significantly, particularly under the SQT1 condition. The vertical lines show that contraction was greatest in the WT condition (Figure 10B) and least in the SQT1 setting (Figure 10C) but due to the incorporation of $I_{\mathrm{sac}}$, contractility was not significantly impaired in either mutation condition, which agrees with available clinical evidence (Schimpf et al., 2008).

\section{DISCUSSION}

\section{SUMMARY OF MAJOR FINDINGS}

Electromechanical coupling in the heart is an active area of research and an important mechanism that couples electrical and mechanical processes is the presence of cardiac ion channels activated by mechanical stimuli such as changes in cell volume or cell stretch (Morris, 1990; Bustamante et al., 1991; Hagiwara et al., 1992; Van Wagoner, 1993; Suleymanian et al., 1995). In the present study, we have developed a family of multi-physical scale models for simulating the electromechanical coupling in the human ventricle at cellular and tissue levels under both WT and SQTS mutation conditions. Using these models we investigated the functional impact of AP abbreviation due to the SQT1 and SQT3 mutations on human ventricular mechanical dynamics. In the heart, SACs transduce mechanical energy into 


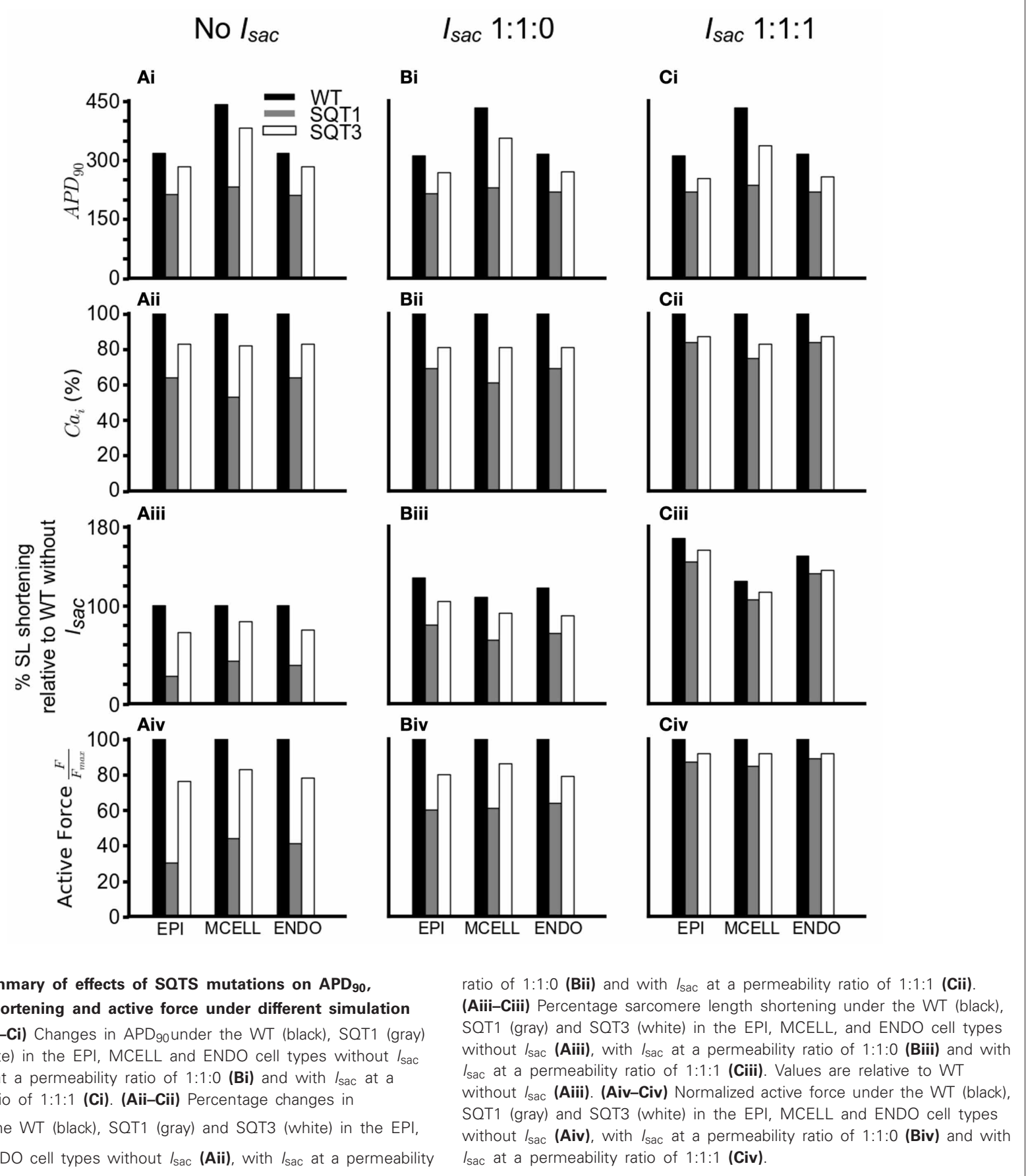

cellular responses and can carry considerable currents (Franz et al., 1992; Alvarez et al., 1999; Calaghan and White, 1999; Calaghan et al., 2003; Youm et al., 2005). Consequently, we incorporated a stretch-activated channel current $\left(I_{\text {sac }}\right)$ into our single cell models to investigate the consequences of its inclusion under WT and SQTS mutation conditions. Our simulations suggest that: (i) at least in silico, abbreviated repolarization in the SQTS has the potential to reduce ventricular mechanical function; (ii) the inclusion of $\left(I_{\mathrm{sac}}\right)$ in the model acts to maintain the normal amplitude of the contractile force (Figures 6-8); and (iii) there is a dissociation between ventricular repolarization and the end of mechanical systole in 3D SQTS simulations (Figure 10), which matches clinical observations by Schimpf et al. (2008). Several aspects of our findings merit more detailed discussion.

\section{MECHANISTIC INSIGHTS}

The results of simulated AP clamp experiments utilizing longer and shorter duration APs in the WT electromechanics model (Figure 4) provide mechanistic insight into the cause of the 
profound reduction and effects on contractility under simulated SQT1 and SQT3 conditions. In these simulations it was shown that markedly reduced contractility was attributable to reduced $\mathrm{SR} \mathrm{Ca}^{2+}$ loading. AP shortening alters cellular electrical

Table 1 | Changes in APD in the EPI, MCELL, and EDO cells with $I_{\text {sac }}$.

\begin{tabular}{lllll}
\hline & & \multicolumn{3}{c}{ APD (ms) } \\
\cline { 3 - 5 } & & No $\boldsymbol{I}_{\text {sac }}$ & $\boldsymbol{I}_{\text {sac }}$ (Permeability & $\begin{array}{l}\boldsymbol{I}_{\text {sac }} \text { (Permeability } \\
\mathbf{1 : 1 : 0 )}\end{array}$ \\
\hline WT & & 310 & 306 \\
& EPI & 317 & 433 & 420 \\
& MCELL & 441 & 310 \\
& ENDO & 317 & 314 & 218 \\
SOT1 & EPI & 212 & 214 & 237 \\
& MCELL & 232 & 230 & 218 \\
\hline SOT3 & ENDO & 211 & 218 & 253 \\
& EPI & 283 & 269 & 336 \\
& MCELL & 382 & 355 & 257 \\
& ENDO & 284 & 270 &
\end{tabular}

dynamics and provides less time for SR $\mathrm{Ca}^{2+}$ loading and therefore $\mathrm{SR} \mathrm{Ca}{ }^{2+}$ content is compromised. This leads to a reduced $\mathrm{SR} \mathrm{Ca}^{2+}$ release and, consequently, cell shortening. These observations are somewhat similar to previously reported effects of K-ATP channel openers. For example, K-ATP channel activation with lemakalim has been reported to reduce ventricular myocyte $\mathrm{Ca}^{2+}$ transients and contraction (Jiang et al., 1994), whilst a second K-ATP channel opener HOE 234 produced a negative inotropic effect on papillary muscle preparations (Kocić and Siluta, 1995).

Our simulation data are suggestive that the presence of SACs attenuates the reduced ventricular cell contractility arising from SQTS K channel mutations. This can be ascribed to the effects of $I_{\text {sac }}$ on SR Ca ${ }^{2+}$ loading and therefore the amplitude of $\left[\mathrm{Ca}^{2+}\right]_{i}$ transients as shown in Figure 8. With $I_{\mathrm{sac}}$, with a Na:K:Ca ratio of either $1: 1: 0$ or $1: 1: 1$, there was a greater $\left[\mathrm{Ca}^{2+}\right]_{i}$ transient amplitude and higher $\mathrm{SR} \mathrm{Ca}^{2+}$ content, resulting in a greater shortening of the SL and active force as compared to the case when $I_{\text {sac }}$ was absent. Such an effect of $I_{\mathrm{sac}}$ on the intracellular $\mathrm{Ca}^{2+}$ handling is due to two factors. First, during the depolarization phase of the $\mathrm{AP}, I_{\mathrm{NaCa}}$ operates in a reverse mode that brings $\mathrm{Ca}^{2+}$ into the cytoplasmic space due to $\mathrm{Na}^{+}$influx. As $I_{\mathrm{sac}}$ is permeable to

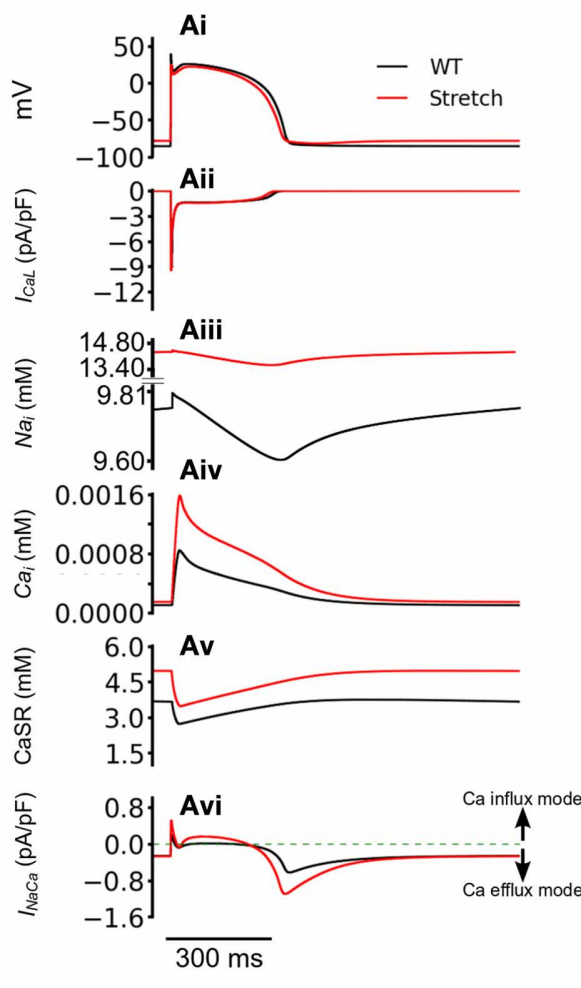

Bi

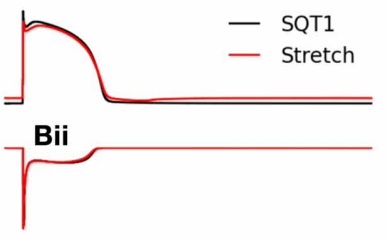

Biii
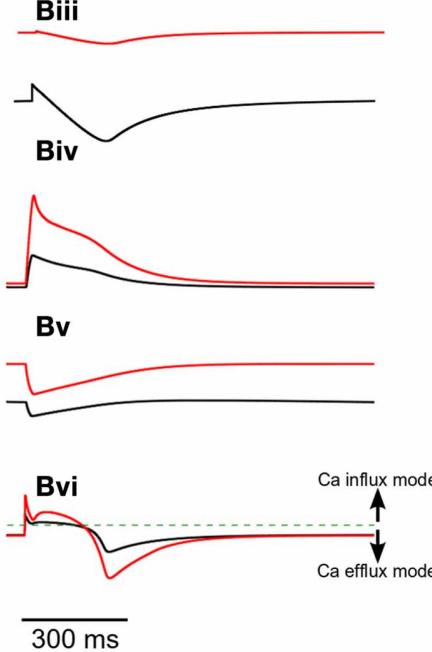

Ci

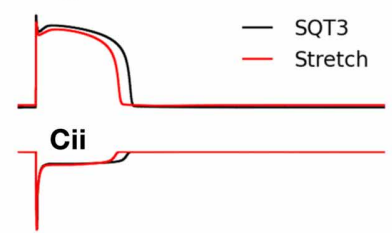

Ciii
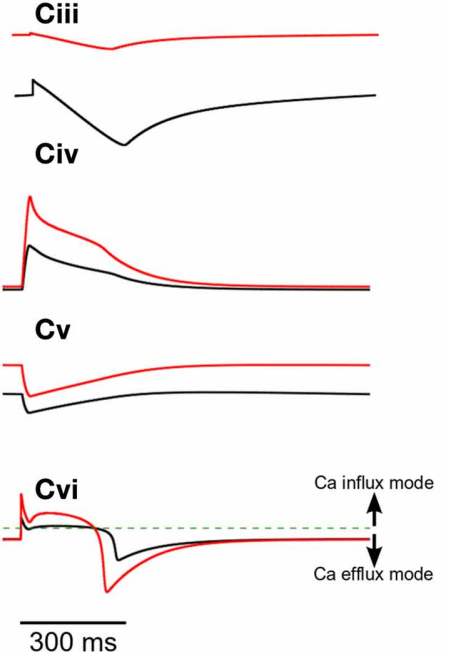

FIGURE 9 | Reverse mode operation of NCX with the incorporation of SAC. (Ai-Ci) Action potentials of WT (Ai), SQT1 (Bi), and SQT3 (Ci) without stretch (black) and with stretch (red). (Aii-Cii) $\left[\mathrm{Na}^{+}\right]_{i}$ for WT (Aii), SOT1 (Bii), and SQT3 (Cii) without stretch (black) and with stretch (red). (Aiii-Ciii) Action potentials of WT (Aiii), SQT1 (Biii), and SQT3 (Ciii) without stretch (black) and with stretch (red). As the SAC is permeable to $\mathrm{Na}^{+}$, it is of higher amplitude under stretch conditions. (Aiv-Civ) $\left[\mathrm{Ca}^{2+}\right]_{i}$ for WT (Aiv), SQT1 (Biv), and SQT3 (Civ) without stretch (black) and with stretch (red). (Av-Cv) SR $\mathrm{Ca}^{2+}$ release under WT (Av), SOT1 (Bv) and SOT3 (Cv) without stretch (black) and with stretch (red). The SR is refilled to a greater level prior to AP initiation under stretch conditions. (Avi-Cvi) $/ /_{\mathrm{NaCa}}$ of WT (Avi), SQT1 (Bvi) and SQT3 (Cvi) without stretch (black) and with stretch (red). 


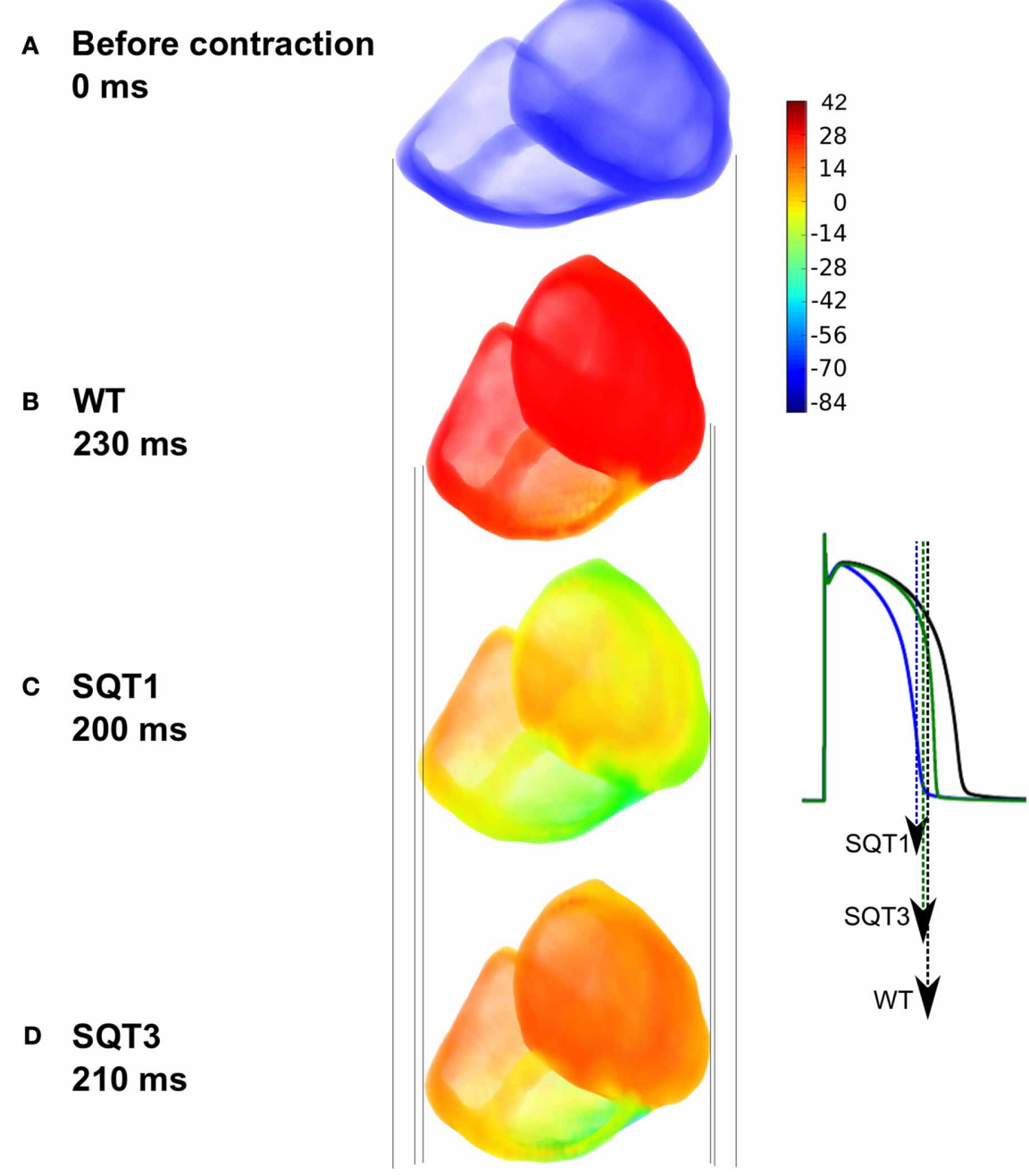

FIGURE 10 | Electromechanical coupling in 3D ventricle model under the SOT1 and SOT3 mutations with $\boldsymbol{I}_{\text {sac }}$. (A) Resting position of the ventricles prior to electrical stimulation. (B) Snapshot of maximum deformation occurring at $230 \mathrm{~ms}$ under the WT condition just at the onset of repolarization (black AP). (C) Snapshot of maximum deformation occurring at $200 \mathrm{~ms}$ under the SQT1 condition. Repolarization is already significantly advanced (blue AP). (D) Snapshot of maximum deformation occurring at $210 \mathrm{~ms}$ under the SQT3 condition. Repolarization is already in progress (green AP). Vertical lines show a comparison of the degree of contraction of the ventricles between the different conditions. Color bar represents the membrane potentials of cells in the ventricles ranging from -86 to $42 \mathrm{mV}$. The APs shown in the inset are from a left ventricular cell under the WT, SQT1 and SQT3 conditions. Arrows indicate the snapshot time shown in the main figure for each condition corresponding to the repolarization time at which maximal deformation occurs.
$\mathrm{Na}^{+}$, the activation of $I_{\mathrm{sac}}$ elevates $\left[\mathrm{Na}^{+}\right]_{i}$, consequentially produces a greater reversed $I_{\mathrm{NaCa}}$ that elevates the $\left[\mathrm{Ca}^{2+}\right]_{i}$ (Figure 9). The elevation of $\left[\mathrm{Na}^{+}\right]_{i}$ leading to the reverse-mode of $I_{\mathrm{NaCa}}$ have been reported by previous studies (Bassingthwaighte et al., 1976; Eisner et al., 1983; Hume and Uehara, 1986; Barcenas-Ruiz et al., 1987; Gannier et al., 1996; Alvarez et al., 1999; Calaghan and White, 1999; Kamkin et al., 2000, 2003; Calaghan et al., 2003; Youm et al., 2005). Secondly, the increased $\left[\mathrm{Ca}^{2+}\right]_{i}$ and the $\mathrm{Ca}^{2+}$ entry via $I_{\mathrm{NaCa}}$ in its reversed mode can both lead to more $\mathrm{Ca}^{2+}$ being pumped back to the SR, contributing to a greater CaSR, and trigger more SR $\mathrm{Ca}^{2+}$ release (Leblanc and Hume, 1990; Levesque et al., 1991; Litwin et al., 1996; Bers, 2001), thereby elevating $\left[\mathrm{Ca}^{2+}\right]_{i}$ (Figure 10).

The dissociation between ventricular repolarization and the end of mechanical systole reflects the difference time course of the two processes. Our simulation data show that relative to ongoing mechanical contraction, ventricular repolarization terminates significantly earlier in SQTS conditions. Thus, accelerated repolarization in the SQTS exacerbates differences between electrical and mechanical events. By way of illustration, in our 3D anatomical human ventricle simulations, at the point of maximum deformation, repolarization was already underway in the SQT1 and SQT3 conditions (Figure 10) whereas it had not begun under the WT condition.

\section{RELEVANCE TO PREVIOUS STUDIES}

Our simulation data suggest that $I_{\text {sac }}$ plays an important role in modulating cardiac electromechanical coupling. This is consistent with previous findings (Hirabayashi et al., 2008; Keldermann et al., 2010). In their study, Keldermann developed a coupled 
electromechanical model for the left human ventricle, and used the model to investigate possible functional roles of $I_{\mathrm{sac}}$ on the re-entrant electrical wave conductions. It was found that mechanoelectrical feedback via $I_{\text {sac }}$ can induce the deterioration of an otherwise stable spiral wave into turbulent wave patterns similar to that of ventricular fibrillation. A similar role for $I_{\mathrm{sac}}$ has also been observed in the study of (Hirabayashi et al., 2008). Findings from the present study add to these previous studies, in demonstrating the important role of $I_{\mathrm{sac}}$ in cardiac electromechanical dynamics.

In relation to the SQTS, Gaita et al. (2003) performed echocardiography, cardiac MRI and stress tests on the two families in which the SQTS was first reported (Gaita et al., 2003) and found no evident structural abnormalities. In subsequent work on mechanical function in the SQTS by Schimpf et al. (2008), no significant difference was seen between control subjects and SQTS patients in end systolic volume, end diastolic volume and ejection fraction. However, a dissociation between ventricular repolarization and the end of mechanical systole was observed. Our 3D simulations (Figure 10) qualitatively match and substantiate this clinical finding (Schimpf et al., 2008).

\section{LIMITATIONS}

In addition to acknowledged limitations of both the TP electrophysiology model (Ten Tusscher and Panfilov, 2006) and the Rice et al. (2008) mechanics model, although our coupled electromechanics model exhibited the Bowditch staircase or Treppe effect (Woodworth, 1902; Mulieri et al., 1992; Lakatta, 2004), it was only qualitatively able to reproduce experimental force-frequency characteristics. In simulations at increased pacing rates from 1.5 to $4 \mathrm{~Hz}$, we observed APD shortening with an increase in the pacing rate, but due to reduced time for $\mathrm{Ca}^{2+}$ extrusion and SR accumulation between successive APs, there was an increase in the amplitude of the $\left[\mathrm{Ca}^{2+}\right]_{i}$ transient and the active force in both WT and SQT settings. This was particularly the case at the faster rates examined, where there was insufficient time for restoration of $\mathrm{Ca}^{2+}$ dynamics between successive APs. These modeling observations require further validation and, if necessary, improvement in $\mathrm{Ca}^{2+}$ dynamics when experimental data become available. However, over the frequency range of $1-2 \mathrm{~Hz}$ our data matched reasonably experimental force-frequency data (Figure 2) and all simulations of the effects of SQT mutations presented here were conducted at $1 \mathrm{~Hz}$. In the ventricular electrophysiology cell models, we did not consider the effects of $\beta$-adrenergic stimulation

\section{REFERENCES}

Adeniran, I., El Harchi, A., Hancox, J. C., and Zhang, H. (2012). Proarrhythmia in KCNJ2-linked short QT syndrome - insights from modelling. Cardiovasc. Res. 94, 66-76. doi: 10.1093/cvr/cvs082

Adeniran, I., McPate, M. J. W., Witchel, H. J., Hancox, J. C., and Zhang, H. (2011). Increased vulnerability of human ventricle to re-entrant excitation in hERG-linked variant 1 short QT syndrome. PLoS Comput. Biol. 7:e1002313. doi: 10.1371/ journal.pcbi.1002313

or more physiologically-detailed $\mathrm{Ca}^{2+}$ handling mechanisms as implemented in some recently published models (Grandi et al., 2010; O'Hara et al., 2011). These effects may affect quantitatively the simulation results (Puglisi et al., 2013). Additionally, due to lack of experimental data on the $I_{\mathrm{sac}}$ in human ventricular myocytes, $I_{\mathrm{sac}}$ density was based on the study of (Panfilov et al., 2005; Youm et al., 2005; Kuijpers, 2008; Kohl and Sachs, 2001; Lunze et al., 2010). Whilst we have investigated the effects of $I_{\mathrm{sac}}$ on attenuation of force reduction in the SQTS setting, it is possible that alternative mechanisms may be involved such as calcium transport controlled by feedback of SR filling via storeoperated $\mathrm{Ca}^{2+}$ channels (SOC) (Kusters et al., 2005; Kowalewski et al., 2006; Berna-Erro et al., 2012). Consequently, in additional simulations (data not shown), we have incorporated into the model a SOC channel current based on the Kuster et al. model (Kusters et al., 2005). In contrast to our findings with $I_{\mathrm{sac}}$, with $I_{S O C}$ incorporation no significant attenuation $(<6 \%)$ of the force reduction in the SQTS settings was observed for the maximal SOC channel conductance varying from 0.2 to $20 \mathrm{pS} / \mathrm{pF}$. Whilst it is important that these potential limitations are stated, they do not fundamentally alter the principal conclusions of this study.

\section{CONCLUSION}

Our tissue simulations qualitatively reproduce and provide a possible explanation for dissociation between the end of mechanical systole and ventricular repolarization (Schimpf et al., 2008): accelerated repolarization under SQTS conditions exacerbates differences in time-course between mechanical and electrical events. The results of the simulations in this study also raise a question as to whether electromechanical coupling involving $I_{\mathrm{sac}}$ offsets a negative inotropic effect of ventricular action potential abbreviation that might otherwise occur for $\mathrm{K}^{+}$-channel linked SQTS. If, in vivo, $I_{\mathrm{sac}}$ does not execute such a role, then it is possible that other compensatory changes exist in SQTS patients as accelerated repolarization might otherwise result in altered SR $\mathrm{Ca}^{2+}$ loading and a reduction in contractile activity.

\section{ACKNOWLEDGMENTS}

This work was supported by project grants from Engineering and Physical Science Research Council UK (EP/J00958X/1; $\mathrm{EP} / \mathrm{I029826/1)}$, the British Heart Foundation (FS/08/021), the Natural Science Foundation of China (61179009) and the University of Manchester.

262-267. doi: 10.1111/j.1542-474X 2009.00308.x

Antzelevitch, C., Pollevick, G. D., Cordeiro, J. M., Casis, O., Sanguinetti, M. C., Aizawa, Y., et al. (2007). Loss-of-function mutations in the cardiac calcium channel underlie a new clinical entity characterized by ST-segment elevation, short QT intervals, and sudden cardiac death. Circulation 115, 442-449. doi: 10.1161/ CIRCULATIONAHA.106.668392

Barcenas-Ruiz, L., Beuckelmann, D. J., and Wier, W. G. (1987)
Sodium-calcium exchange in heart: membrane currents and changes in $[\mathrm{Ca} 2+]_{i}$. Science 238, 1720-1722. doi: 10.1126/science. 3686010

Bassingthwaighte, J. B., Fry, C. H., and McGuigan, J. A. (1976). Relationship between internal calcium and outward current in mammalian ventricular muscle; a mechanism for the control of the action potential duration. J. Physiol. (Lond.) 262, 15-37.

Bellocq, C., van Ginneken, A. C. G., Bezzina, C. R., Alders, M., Escande, D., Mannens, M. M. A. 
M., et al. (2004). Mutation in the KCNQ1 gene leading to the short QT-interval syndrome. Circulation 109, 2394-2397. doi: 10.1161/01. CIR.0000130409.72142.FE

Berna-Erro, A., Redondo, P. C., and Rosado, J. A. (2012). Store-operated $\mathrm{Ca}(2+)$ entry. Adv. Exp. Med. Biol. 740, 349-382. doi: 10.1007/978-94007-2888-2_15

Bers, D. (2001). Excitation-Contraction Coupling and Cardiac Contractile Force. 2nd Edn. Dordrecht: Springer. doi: 10.1007/978-94-010-0658-3

Bett, G. C., and Sachs, F. (1997). Cardiac mechanosensitivity and stretch-activated ion channels. Trends Cardiovasc. Med. 7, 4-8. doi: 10.1016/S1050-1738(96)00119-3

Bogaert, J., and Rademakers, F. E. (2001). Regional nonuniformity of normal adult human left ventricle. Am. J. Physiol. Heart Circ. Physiol. 280, H610-H620.

Boland, J., and Troquet, J. (1980). Intracellular action potential changes induced in both ventricles of the rat by an acute right ventricular pressure overload. Cardiovasc. Res. 14, 735-740. doi: 10.1093/cvr/ 14.12.735

Bonet, J., and Wood, R. D. (2008). Nonlinear Continuum Mechanics for Finite Element Analysis, 2nd Edn. New York, NY: Cambridge University Press. doi: 10.1017/ CBO9780511755446

Braess, D. (2007). Finite Elements: Theory, Fast Solvers, and Applications in Solid Mechanics, 3rd Edn. New York, NY: Cambridge University Press. doi: 10.1017/ CBO9780511618635

Brenner, S. C., and Scott, R. (2010). The Mathematical Theory of Finite Element Methods. Softcover Reprint of Hardcover, 3rd Edn. 2008. New York, NY: Springer.

Brugada, R., Hong, K., Dumaine, R., Cordeiro, J., Gaita, F., Borggrefe, M., et al. (2004). Sudden death associated with short-QT syndrome linked to mutations in HERG. Circulation 109, 30-35. doi: 10.1161/01.CIR.0000109482. 92774.3A

Burnett, D. S. (1987). Finite Element Analysis: From Concepts to Applications, 1st Edn. Reading, MA: Addison Wesley.

Bustamante, J. O., Ruknudin, A., and Sachs, F. (1991). Stretchactivated channels in heart cells: relevance to cardiac hypertrophy. J. Cardiovasc. Pharmacol. 17(Suppl. 2), S110-S113. doi: 10.1097/ 00005344-199117002-00024

Calaghan, S. C., Belus, A., and White, E. (2003). Do stretch-induced changes in intracellular calcium modify the electrical activity of cardiac muscle. Prog. Biophys. Mol. Biol. 82, 81-95. doi: $\quad$ 10.1016/S0079-6107(03) 00007-5

Calaghan, S. C., and White, E. (1999). The role of calcium in the response of cardiac muscle to stretch. Prog. Biophys. Mol. Biol. 71, 59-90. doi: 10.1016/S0079-6107(98)00037-6

Chamberland, í., Fortin, A., and Fortin, M. (2010). Comparison of the performance of some finite element discretizations for large deformation elasticity problems. Comput. Struct. 88, 664-673.

Cheng, A., Nguyen, T. C., Malinowski, M., Daughters, G. T., Miller, D. C., and Ingels, N. B. Jr. (2008). Heterogeneity of left ventricular wall thickening mechanisms. Circulation 118, 713-721. doi: 10.1161/CIRCULATIONAHA. 107.744623

Cohen, S., Alan, and Hindmarsh, C. (1996). "Cvode, a stiff/nonstiff ode solver in, C.," in C. Computers in Physics, ed L. M. Holmes (New York, NY: American Institute of Physics Inc.), 138-143.

Colli Franzone, P., Pavarino, L. F., and Taccardi, B. (2005). Simulating patterns of excitation, repolarization and action potential duration with cardiac bidomain and monodomain models. Math. Biosci. 197, 35-66. doi: 10.1016/j.mbs. 2005.04.003

Coppola, B. A., and Omens, J. H. (2008). Role of tissue structure on ventricular wall mechanics. Mol. Cell. Biomech. 5, 183-196.

Costa, K. D., Holmes, J. W., and Mcculloch, A. D. (2001). Modelling cardiac mechanical properties in three dimensions. Phil. Trans. $R$. Soc. Lond. A 359, 1233-1250. doi: 10.1098/rsta.2001.0828

Couderc, J.-P., and Lopes, C. M. (2010). Short and long QT syndromes: does QT length really matter. J. Electrocardiol. 43, 396-399. doi: 10.1016/j.jelectrocard.2010.07.009

Cross, B., Homoud, M., Link, M., Foote, C., Garlitski, A., Weinstock, J., et al. (2011). The short QT syndrome. J. Int. Cardiac Electrophysiol. 31, 25-31. doi: 10.1007/s10840-0119566-0

Deo, M., Ruan, Y., Pandit, S. V., Shah, K., Berenfeld, O., Blaufox, A., et al. (2013). KCNJ2 mutation in short QT syndrome 3 results in atrial fibrillation and ventricular proarrhythmia. Proc. Natl. Acad. Sci. U.S.A. 110, 4291-4296. doi: 10.1073/pnas.1218154110

Eisner, D. A., Lederer, W. J., and Vaughan-Jones, R. D. (1983). The control of tonic tension by membrane potential and intracellular sodium activity in the sheep cardiac Purkinje fibre. J. Physiol. (Lond.) 335, 723-743

Ern, A., and Guermond, J.-L. (2010). Theory and Practice of Finite Elements. Softcover reprint of Hardcover, 1st Edn., 2004. New York, NY: Springer.

Extramiana, F., and Antzelevitch, C. (2004). Amplified transmural dispersion of repolarization as the basis for arrhythmogenesis in a canine ventricular-wedge model of short-QT syndrome. Circulation 110, 3661-3666. doi: 10.1161/01. CIR.0000143078.48699.0C

Franz, M. R. (1996). Mechanoelectrical feedback in ventricular myocardium. Cardiovasc. Res. 32, 15-24.

Franz, M. R., Cima, R., Wang, D., Profitt, D., and Kurz, R. (1992). Electrophysiological effects of myocardial stretch and mechanical determinants of stretch-activated arrhythmias. Circulation 86, 968-978. doi: 10.1161/01.CIR. 86.3.968

Gaita, F., Giustetto, C., Bianchi, F., Wolpert, C., Schimpf, R., Riccardi, R., et al. (2003). Short QT Syndrome: a familial cause of sudden death. Circulation 108, 965-970. doi: 10.1161/01.CIR 0000085071.28695.C4

Gannier, F., White, E., Garnier, and Le Guennec, J. Y. (1996). A possible mechanism for large stretchinduced increase in $[\mathrm{Ca} 2+]_{i}$ in isolated guinea-pig ventricular myocytes. Cardiovasc. Res. 32, 158-167.

Gima, K., and Rudy, Y. (2002). Ionic current basis of electrocardiographic waveforms: a model study. Circ. Res. 90, 889-896. doi: 10.1161/ 01.RES.0000016960.61087.86

Giustetto, C., Di Monte, F., Wolpert, C. Borggrefe, M., Schimpf, R., Sbragia, P., et al. (2006). Short QT syndrome: clinical findings and diagnostictherapeutic implications. Eur. Heart J. 27, 2440-2447. doi: 10.1093/ eurheartj/ehl185

Gollob, M. H., Redpath, C. J., and Roberts, J. D. (2011). The short QT syndrome: proposed diagnostic criteria. J. Am. Coll. Cardiol. 57, 802-812. doi: 10.1016/j.jacc.2010. 09.048

Grandi, E., Pasqualini, F. S., and Bers, D. M. (2010). A novel computational model of the human ventricular action potential and $\mathrm{Ca}$ transient. J. Mol. Cell. Cardiol. 48, 112-121. doi: 10.1016/j.yjmcc.2009. 09.019
Guccione, J. M., McCulloch, A. D., and Waldman, L. K. (1991). Passive material properties of intact ventricular myocardium determined from a cylindrical model. J. Biomech. Eng. 113, 42-55. doi: 10.1115/1.289 4084

Gussak, I., Brugada, P., Brugada, J., Wright, R. S., Kopecky, S. L., Chaitman, B. R., et al. (2000). Idiopathic short QT interval: a new clinical syndrome. Cardiology 94 99-102. doi: 10.1159/000047299

Haga, J. B., Osnes, H., and Langtangen, H. P. (2012). On the causes of pressure oscillations in low-permeable and low-compressible porous media. Int. J. Num. Anal. Methods Geomech. 36, 1507-1522. doi: 10.1002/nag.1062

Hagiwara, N., Masuda, H., Shoda, M., and Irisawa, H. (1992). Stretchactivated anion currents of rabbit cardiac myocytes. J. Physiol. (Lond.) 456, 285-302.

Hancox, J. C., McPate, M. J., Harchi, A., Duncan, R. S., Dempsey, C. E., Witchel, H. J., et al. (2011). "The Short QT Syndrome, " in Heart Rate and Rhythm, eds. O. N. Tripathi, U. Ravens, and M. C. Sanguinetti (Berlin, Heidelberg: Springer Berlin Heidelberg), 431-449. Available online at: http://www.springerlink. com/content/m818618n3h81w43m/ [Accessed July 10, 2011].

Hattori, T., Makiyama, T., Akao, M., Ehara, E., Ohno, S., Iguchi, M., et al. (2011). A novel gain-of-function KCNJ2 mutation associated with short QT syndrome impairs inward rectification of Kir2.1 currents. Cardiovas. Res. 666-673. doi: $10.1093 / \mathrm{cvr} / \mathrm{cvr} 329$

Hindmarsh, A. C., Brown, P. N., Grant, K. E., Lee, S. L., Serban, R., Shumaker, D. E., et al. (2005). SUNDIALS: suite of nonlinear and differential/algebraic equation solvers. ACM Trans. Math. Softw. 31, 363-396. doi: 10.1145/1089014. 1089020

Hirabayashi, S., Inagaki, M., and Hisada, T. (2008). Effects of wall stress on the dynamics of ventricular fibrillation: a simulation study using a dynamic mechanoelectric model of ventricular tissue. J. Cardiovasc. Electrophysiol. 19, 730-739. doi: 10.1111/j.1540-8167. 2008.01099.x

Holzapfel, G. A. (2000). Nonlinear Solid Mechanics: A Continuum Approach for Engineering, 1st Edn. Chichester: Wiley.

Hong, K., Bjerregaard, P., Gussak, I., and Brugada, R. (2005a). Short QT syndrome and atrial fibrillation caused by mutation in $\mathrm{KCNH} 2$. 
J. Cardiovasc. Electrophysiol 16, 394-396. doi: 10.1046/j.1540-8167. 2005.40621.x

Hong, K., Piper, D. R., DiazValdecantos, A., Brugada, J., Oliva, A., Burashnikov, E., et al. (2005b). De novo KCNQ1 mutation responsible for atrial fibrillation and short QT syndrome in utero. Cardiovasc. Res. 68, 433-440. doi: 10.1016/j.cardiores.2005.06.023

Hu, H., and Sachs, F. (1997). Stretchactivated ion channels in the heart. J. Mol. Cell. Cardiol. 29, 1511-1523. doi: 10.1006/jmcc.1997.0392

Hughes, T. J. R. (2000). The Finite Element Method: Linear Static and Dynamic Finite Element Analysis. New Jersey, NJ: Dover Publications.

Hume, J. R., and Uehara, A. (1986). "Creep currents" in single frog atrial cells may be generated by electrogenic $\mathrm{Na} / \mathrm{Ca}$ exchange. J. Gen. Physiol. 87, 857-884. doi: 10.1085/ jgp.87.6.857

Hunter, P. J., Nash, M. P., and Sands, G. B. (1997). "Computational Mechanics of the Heart," in Computational Biology of the Heart, eds. A. V. Panfilov and A. V. Holden (West Sussex: Wiley), 345-407.

Isenberg, G., Kazanski, V., Kondratev, D., Gallitelli, M. F., Kiseleva, I., and Kamkin, A. (2003). Differential effects of stretch and compression on membrane currents and $[\mathrm{Na}+]_{\mathrm{c}}$ in ventricular myocytes. Prog. Biophys. Mol. Biol. 82, 43-56. doi: $\quad 10.1016 / S 0079-6107(03)$ 00004-X

Jiang, C., Mochizuki, S., Poole-Wilson, P. A., Harding, S. E., and MacLeod, K. T. (1994). Effect of lemakalim on action potentials, intracellular calcium, and contraction in guinea pig and human cardiac myocytes. Cardiovasc. Res. 28, 851-857. doi: $10.1093 / \mathrm{cvr} / 28.6 .851$

Kamkin, A., Kiseleva, I., and Isenberg, G. (2000). Stretch-activated currents in ventricular myocytes: amplitude and arrhythmogenic effects increase with hypertrophy. Cardiovasc. Res. 48, 409-420. doi: 10.1016/S0008-6363(00)00208-X

Kamkin, A., Kiseleva, I., and Isenberg, G. (2003). Ion selectivity of stretch-activated cation currents in mouse ventricular myocytes. Pflugers Arch. 446, 220-231.

Keener, J., and Sneyd, J. (2008). Mathematical Physiology: II: Systems Physiology, 2nd Edn. New York, NY: Springer.

Keldermann, R. H., Nash, M. P., Gelderblom, H., Wang, V. Y., and Panfilov, A. V. (2010). Electromechanical wavebreak in a model of the human left ventricle. Am. J. Physiol. Heart Circ. Physiol. 299, H134-H143. doi: 10.1152/ajpheart.00862.2009

Keller, D. U. J., Kalayciyan, R., Dössel, O., and Seemann, G. (2009). "Fast creation of endocardial stimulation profiles for the realistic simulation of body surface ECGs," in IFMBE Proceedings, 145-148. Available online at: http://www.scopus.com/inward/ record.url?eid=2-s2.0-77950134835 andpartnerID $=40$ andmd $5=2 \mathrm{db} 2 \mathrm{~b} 8$ 9cc19de5e28ec01ebbf0dffffo [Accessed July 20, 2011]. doi: 10.1007/ 978-3-642-03882-2_37

Kocić, I., and Siluta, W. (1995). Cardiopharmacological profile of HOE 234, the new activator of ATP-sensitive $\mathrm{K}+$ channels in the guinea pig heart. Pol. J. Pharmacol. $47,457-460$.

Kohl, P., Hunter, P., and Noble, D. (1999). Stretch-induced changes in heart rate and rhythm: clinical observations, experiments and mathematical models. Prog. Biophys. Mol. Biol. 71, 91-138. doi: 10.1016/S0079-6107 (98)00038-8

Kohl, P., and Sachs, F. (2001). Mechanoelectric feedback in cardiac cells. Phil. Trans. R. Soc. Lond. A 359, 1173-1185. doi: 10.1098/rsta.2001.0824

Kowalewski, J. M., Uhlén, P., Kitano, H., and Brismar, $\mathrm{H}$. (2006). Modeling the impact of store-operated Ca2+ entry on intracellular $\mathrm{Ca} 2+$ oscillations. Math. Biosci. 204, 232-249. doi: 10.1016/j. mbs.2006.03.001

Kuijpers, N. H. L. (2008) Cardiac Electrophysiology and Mechanoelectric Feedback. $\mathrm{PhD}$ thesis. Eindhoven: Eindhoven University of Technology.

Kusters, J. M. A. M., Dernison, M. M., van Meerwijk, W. P. M., Ypey, D. L., Theuvenet, A. P. R., and Gielen, C. C. A. M. (2005). Stabilizing role of calcium store-dependent plasma membrane calcium channels in action-potential firing and intracellular calcium oscillations. Biophys. J. 89, 3741-3756. doi: 10.1529/biophysj.105.062984

Lab, M. J. (1982). Contractionexcitation feedback in myocardium. Physiol. Basis Clin. Relevance. Circ. Res. 50, 757-766. doi: 10.1161/01. RES.50.6.757

Lab, M. J. (1996). Mechanoelectric feedback (transduction) in heart: concepts and implications. Cardiovasc. Res. 32, 3-14.

Lakatta, E. G. (2004). Beyond Bowditch: the convergence of cardiac chronotropy and inotropy. Cell Calcium 35, 629-642. doi: 10.1016/j.ceca.2004.01.017

Land, S., Niederer, S. A., and Smith, N. P. (2012). Efficient computational methods for strongly coupled cardiac electromechanics. IEEE Trans. Biomed. Eng. 59, 1219-1228. doi: 10.1109/TBME. 2011.2112359

Leblanc, N., and Hume, J. R. (1990). Sodium current-induced release of calcium from cardiac sarcoplasmic reticulum. Science 248, 372-376. doi: $10.1126 /$ science. 2158146

Legrice, I. J., Hunter, P. J., and Smaill, B. H. (1997). Laminar structure of the heart: a mathematical model. Am. J. Physiol. 272, H2466-H2476.

Levesque, P. C., Leblanc, N., and Hume, J. R. (1991). Role of reversemode $\mathrm{Na}(+)-\mathrm{Ca} 2+$ exchange in excitation-contraction coupling in the heart. Ann. N.Y. Acad. Sci. 639 , 386-397. doi: 10.1111/j.1749-6632. 1991.tb17327.x

Lilli, A., Baratto, M. T., Meglio, J. D., Chioccioli, M., Magnacca, M. Talini, E., et al. (2013). Left ventricular rotation and twist assessed by four-dimensional speckle tracking echocardiography in healthy subjects and pathological remodeling: a single center experience. Echocardiography 30, 171-179. doi 10.1111/echo.12026

Lions, J. L., and Ciarlet, P. G. (1994). Handbook of Numerical Analysis; Vol.3, Techniques of Scientific Computing (part 1) Numerical methods for solids (part 1); Solution of equations in $R(n)$ (part 2). London: NorthHolland Available online at: http://catalogue.library.manchester. ac.uk/items/815424 [Accessed April 25, 2013].

Litwin, S., Kohmoto, O., Levi, A. J., Spitzer, K. W., and Bridge, J. $\mathrm{H}$ (1996). Evidence that reverse $\mathrm{Na}$ Ca exchange can trigger SR calcium release. Ann. N.Y. Acad. Sci. 779, 451-463. doi: 10.1111/j.1749-6632 1996.tb44820.x

Logg, A., Mardal, K.-A., and Wells, G. eds. (2012). Automated Solution of Differential Equations by the Finite Element Method: The FEniCS Book. 2012th Edn. Heidelberg: Springer.

Lorenz, C. H., Pastorek, J. S., and Bundy, J. M. (2000). Delineation of normal human left ventricular twist throughout systole by tagged cine magnetic resonance imaging. J. Cardiovasc. Magn Reson. 2, 97-108. doi: 10.3109/ 10976640009148678
Lunze, K., Stålhand, J., and Leonhardt, S. (2010). "Modeling of stretchactivated sarcolemmal channels in smooth muscle cells," in World Congress on Medical Physics and Biomedical Engineering, September 7 - 12 2009, Munich, Germany IFMBE Proceedings, eds O. Dössel and W. C. Schlegel (Springer Berlin Heidelberg), 740-743. Available online at: http://www.springerlink com/content/k3052r8670832k70/ab stract/ [Accessed September 20, 2012].

MacGowan, G. A., Shapiro, E. P., Azhari, H., Siu, C. O., Hees, P. S., Hutchins, G. M., et al. (1997). Noninvasive measurement of shortening in the fiber and cross-fiber directions in the normal human left ventricle and in idiopathic dilated cardiomyopathy. Circulation 96, 535-541. doi: 10.1161/01.CIR. 96.2 .535

Marsden, J. E., and Hughes, T. J. R. (1994). Mathematical Foundations of Elasticity. New Jersey, NJ: Dover Publications.

McIntosh, M. A., Cobbe, S. M., and Smith, G. L. (2000). Heterogeneous changes in action potential and intracellular $\mathrm{Ca} 2+$ in left ventricular myocyte sub-types from rabbits with heart failure. Cardiovasc. Res. 45, 397-409. doi: 10.1016/S00086363(99)00360-0

Morris, C. E. (1990). Mechanosensitive ion channels. J. Membr. Biol. 113 93-107. doi: 10.1007/BF01872883

Mulieri, L. A., Hasenfuss, G., Leavitt, B., Allen, P. D., and Alpert, N. R. (1992). Altered myocardial forcefrequency relation in human heart failure. Circulation 85, 1743-1750. doi: 10.1161/01.CIR.85.5.1743

Nash, M. P., and Panfilov, A. V. (2004). Electromechanical model of excitable tissue to study reentrant cardiac arrhythmias. Prog. Biophys. Mol. Biol. 85, 501-522. doi: 10.1016/ j.pbiomolbio.2004.01.016

Niederer, S. A., and Smith, N. P. (2008). An improved numerical method for strong coupling of excitation and contraction models in the heart. Prog. Biophys. Mol. Biol. 96, 90-111. doi: 10.1016/j.pbiomolbio. 2007.08.001

O'Hara, T., Virág, L., Varró, A., and Rudy, Y. (2011). Simulation of the undiseased human cardiac ventricular action potential: model formulation and experimental validation. PLoS Comput. Biol. 7: e1002061. doi: 10.1371/journal.pcbi.1002061

Panfilov, A. V., Keldermann, R. H., and Nash, M. P. (2005). Self-organized pacemakers in a coupled reactiondiffusion-mechanics system. Phys. 
Rev. Lett. 95, 258104. doi: 10.1103/ PhysRevLett.95.258104

Patel, C., and Antzelevitch, C. (2008). Cellular basis for arrhythmogenesis in an experimental model of the SQT1 form of the short QT syndrome. Heart Rhythm 5, 585-590. doi: 10.1016/j.hrthm.2008.01.022

Patel, U., and Pavri, B. B. (2009). Short QT syndrome: a review. Cardiol. Rev. 17, 300-303. doi: 10.1097/CRD. 0b013e3181c07592

Pathmanathan, P., and Whiteley, J. P. (2009). A numerical method for cardiac mechanoelectric simulations. Ann. Biomed. Eng. 37, 860-873. doi: 10.1007/s10439-0099663-8

Potse, M., Dubé, B., Richer, J., Vinet, A., and Gulrajani, R. M. (2006). A comparison of monodomain and bidomain reaction-diffusion models for action potential propagation in the human heart. IEEE Trans. Biomed. Eng. 53, 2425-2435. doi: 10.1109/ TBME.2006.880875

Priori, S. G., Pandit, S. V., Rivolta, I., Berenfeld, O., Ronchetti, E., Dhamoon, A., et al. (2005). A novel form of short QT syndrome (SQT3) is caused by a mutation in the KCNJ2 gene. Circ. Res 96, 800-807. doi: 10.1161/01.RES.0000162101. $76263.8 \mathrm{c}$

Puglisi, J. L., Negroni, J. A., ChenIzu, Y., and Bers, D. M. (2013). The force-frequency relationship: insights from mathematical modeling. Adv. Physiol. Educ. 37, 28-34. doi: 10.1152/advan.00072.2011

Rice, J. J., Wang, F., Bers, D. M., and de Tombe, P. P. (2008). Approximate model of cooperative activation and crossbridge cycling in cardiac muscle using ordinary differential equations. Biophys. J. 95, 2368-2390. doi: 10.1529/biophysj.107.119487

Rush, S., and Larsen, H. (1978). A practical algorithm for solving dynamic membrane equations. IEEE Trans. Biomed. Eng. 25, 389-392. doi: 10.1109/TBME.1978.326270

Schimpf, R., Antzelevitch, C., Haghi, D., Giustetto, C., Pizzuti, A., Gaita, F., et al. (2008). Electromechanical coupling in patients with the short QT syndrome: further insights into the mechanoelectrical hypothesis of the $\mathrm{U}$ wave. Heart Rhythm 5, 241-245. doi: 10.1016/j.hrthm. 2007.10.015
Schimpf, R., Wolpert, C., Gaita, F., Giustetto, C., and Borggrefe, M. (2005). Short QT syndrome. Cardiovasc. Res 67, 357-366. doi: 10.1016/j.cardiores.2005.03.026

Seemann, G., Keller, D. U. J., Weiss, D. L., and Dössel, O. (2006). "Modeling human ventricular geometry and fiber orientation based on diffusion tensor MRI," in Computers in Cardiology, 801-804. Available online at: http://www.scopus.com/ inward/record.url?eid=2-s2.0-38049 006338andpartnerID $=40$ andmd5 $=$ d7c99be0309654b17513e9b39ee96 029 [Accessed July 20, 2011].

Suleymanian, M. A., Clemo, H. F., Cohen, N. M., and Baumgarten, C. M. (1995). Stretch-activated channel blockers modulate cell volume in cardiac ventricular myocytes. J. Mol. Cell. Cardiol. 27, 721-728. doi: 10.1016/S0022-2828 (08)80062-4

Sun, Y., Quan, X.-Q., Fromme, S., Cox, R. H., Zhang, P., Zhang, L., et al. (2011). A novel mutation in the KCNH2 gene associated with short QT syndrome. J. Mol. Cell. Cardiol. 50, 433-441. doi: 10.1016/j.yjmcc. 2010.11.017

Sundnes, J., Lines, G. T., and Tveito, A. (2005). An operator splitting method for solving the bidomain equations coupled to a volume conductor model for the torso. Math. Biosci. 194, 233-248. doi: 10.1016/j. mbs.2005.01.001

Taggart, P. (1996). Mechano-electric feedback in the human heart. Cardiovasc. Res. 32, 38-43.

Taggart, P., Sutton, P. M., Opthof, T., Coronel, R., Trimlett, R., Pugsley, W., et al. (2000). Inhomogeneous transmural conduction during early ischaemia in patients with coronary artery disease. J. Mol. Cell. Cardiol 32, 621-630. doi: 10.1006/ jmcc.2000.1105

Templin, C., Ghadri, J.-R., Rougier, J.-S., Baumer, A., Kaplan, V., Albesa, M., et al. (2011). Identification of a novel loss-of-function calcium channel gene mutation in short QT syndrome (SQTS6). Eur. Heart J. 32, 1077-1088. doi: 10.1093/eurheartj/ ehr076

Trayanova, N., Li, W., Eason, J., and Kohl, P. (2004). Effect of stretchactivated channels on defibrillation efficacy. Heart Rhythm 1, 67-77. doi: 10.1016/j.hrthm.2004.01.002

Tseng, W.-Y. I., Reese, T. G., Weisskoff, R. M., Brady, T. J., and Wedeen, V. J. (2000). Myocardial fiber shortening in humans: Initial results of MR imaging. Radiology 216, 128-139.

Ten Tusscher, K. H. W. J., Noble, D. Noble, P. J., and Panfilov, A. V. (2004). A model for human ventricular tissue. Am. J. Physiol. Heart Circ. Physiol 286, H1573-H1589. doi: 10.1152/ajpheart.00794.2003

Ten Tusscher, K. H. W. J., and Panfilov, A. V. (2006). Alternans and spiral breakup in a human ventricular tissue model. Am. J. Physiol. Heart Circ. Physiol 291, H1088-H1100. doi: 10.1152/ ajpheart.00109.2006

Van Wagoner, D. R. (1993). Mechanosensitive gating of atrial ATP-sensitive potassium channels. Circ. Res. 72, 973-983. doi: 10.1161/ 01.RES.72.5.973

Weiss, D. L., Seemann, G., Sachse, F. B., and Dössel, O. (2005). Modelling of short QT syndrome in a heterogeneous model of the human ventricular wall. Europace 7(Suppl. 2), 105-117. doi: 10.1016/j.eupc.2005. 04.008

Whiteley, J. P., Bishop, M. J., and Gavaghan, D. J. (2007). Soft tissue modelling of cardiac fibres for use in coupled mechano-electric simulations. Bull. Math. Biol. 69, 2199-2225. doi: 10.1007/s11538007-9213-1

Woodworth, R. S. (1902). Maximal contraction, "staircase" contraction, refractory period, and compensatory pause, of the heart. Am. J. Physiol. 8, 213-249.

Xia, L., Zhang, Y., Zhang, H., Wei, Q., Liu, F., and Crozier, S. (2006). Simulation of Brugada syndrome using cellular and threedimensional whole-heart modeling approaches. Physiol. Meas. 27, 1125-1142. doi: 10.1088/09673334/27/11/006

Youm, J. B., Han, J., Kim, N., Zhang, Y.-H., Kim, E., Leem, C. H., et al. (2005). "role of stretch-activated channels in the heart: action potential and $\mathrm{Ca} 2+$ transients mechanosensitivity in cells and tissues - NCBI bookshelf," in eds A. Kamkin and I. Kiseleva (Moscow: Academia). Available online at: http://www.ncbi.nlm.nih.gov/ books/NBK7490/ [Accessed September 15, 2012].

Zabel, M., Koller, B. S., Sachs, F., and Franz, M. R. (1996). Stretchinduced voltage changes in the isolated beating heart: importance of the timing of stretch and implications for stretch-activated ion channels. Cardiovasc. Res. 32, 120-130.

Zhang, H., and Hancox, J. C. (2004). In silico study of action potential and QT interval shortening due to loss of inactivation of the cardiac rapid delayed rectifier potassium current. Biochem. Biophys. Res. Commun. 322, 693-699. doi: 10.1016/j.bbrc.2004.07.176

Zhang, H., Kharche, S., Holden, A. V., and Hancox, J. C. (2008) Repolarisation and vulnerability to re-entry in the human heart with short QT syndrome arising from KCNQ1 mutation-a simulation study. Prog. Biophys. Mol. Biol 96, 112-131. doi: 10.1016/j. pbiomolbio.2007.07.020

Conflict of Interest Statement: The authors declare that the research was conducted in the absence of any commercial or financial relationships that could be construed as a potential conflict of interest.

Received: 25 April 2013; paper pending published: 14 May 2013; accepted: 14 June 2013; published online: 05 July 2013.

Citation: Adeniran I, Hancox JC and Zhang $H$ (2013) In silico investigation of the short QT syndrome, using human ventricle models incorporating electromechanical coupling. Front. Physiol. 4:166. doi: 10.3389/fphys. 2013.00166

This article was submitted to Frontiers in Cardiac Electrophysiology, a specialty of Frontiers in Physiology.

Copyright (c) 2013 Adeniran, Hancox and Zhang. This is an open-access article distributed under the terms of the Creative Commons Attribution License, which permits use, distribution and reproduction in other forums, provided the original authors and source are credited and subject to any copyright notices concerning any third-party graphics etc. 